Sultan Qaboos University Journal of Arts \& Social Sciences

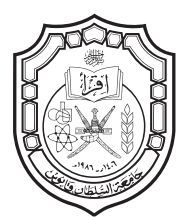

جامعة السلطان قابوس الادمان مجلة الآداب والعلوم الاجتمأعية

\title{
تقييم تجربة الرعاية الاجتماعية للمسنين من وجهة نظر المستفيدين
}

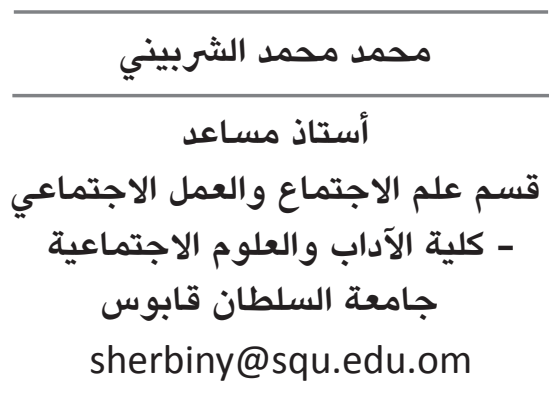

$$
\begin{aligned}
& \text { أحلام بنت حميد بن سعيد المنذرية } \\
& \text { باحثة } \\
& \text { قسم علم الاجتماع والعمل الاجتماعي } \\
& \text { - كلية الآداب والعلوم الاجتماعماعية الاجنماعية } \\
& \text { جامعة السلطان قابوس الاجس }
\end{aligned}
$$

ahlam.squoman@hotmail.com 


\title{
تقييم تجربة الرعاية الاجتماعية للمسنين \\ من وجهة نظر المستفيدين
}

أحلام بنت حميد بن سعيد المنذرية، و محمد محمد الشربيني

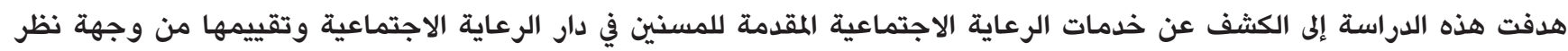

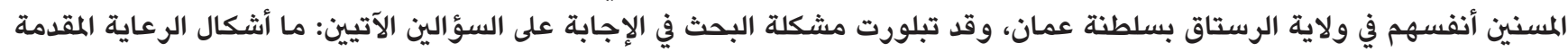

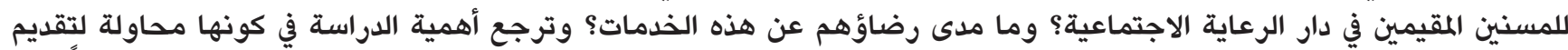

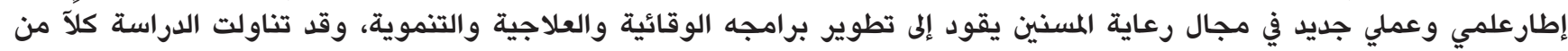

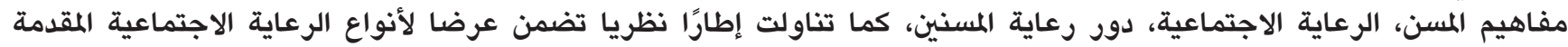

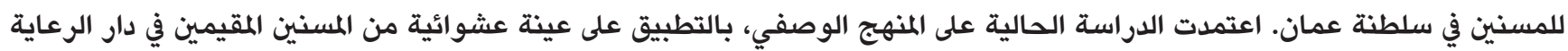

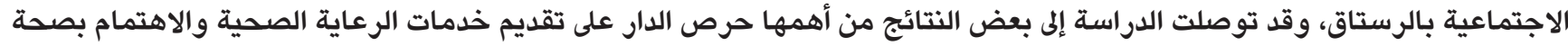

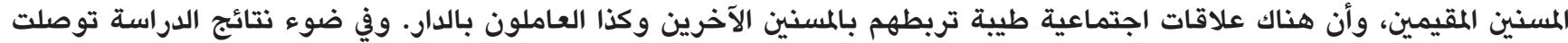

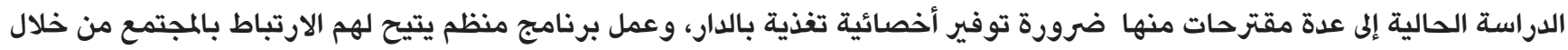
القيام بالأنشطة الخارجية مما يشعرهم بالصحة النفسية ويقلل من شعورهم بالية بالوحدة.

الكلمات المفتاحية: التقييم، الرعاية الاجتماعية، المسنين.

\section{Evaluation of the experience of social welfare for the elderly from the point of view of beneficiaries}

\author{
Ahlam Al-Mandhri and Mohamed Elsherbiny
}

\section{Abstract:}

The purpose of this study was to identify and assess the social care services provided to the elderly in the Social Care home by the elderly themselves in the state of Al Rustaq in Oman. The problem of the research was to answer the following questions: What forms of care are provided to the elderly residing in the social care home? And the extent of their satisfaction with these services, and the importance of the study is an attempt to provide a new scientific and practical framework in the care of the elderly leading to the development of preventive programs, therapeutic and development, and the study dealt with the concepts of aging.The study tackled the concepts of the elderly, social welfare, nursing homes and a theoretical framework that included a presentation of the types of social care provided to the elderly in the Sultanate of Oman. The study was based on a descriptive approach, applied to a random sample of elderly residents of the social care home in Rustaq. The study reached some results, the most important of which is the care of thehome to provide health care services and attention to the health of elderly residents. The study was based on a descriptive approach, applied to a random sample of elderly residents of the social care home in Rustaq. The study reached some results, the most important of which is the care of the home to provide health care services and attention to the health of elderly residents. Baldar. In light of the results of the study, the current study has reached several proposals, including the need to provide nutritionist in the house, and the work of an organized program that allows them to connect with the community through external activities, which makes them mental health and reduce their sense of loneliness.

Keywords: Evaluation; Welfare; The elderly. 
وملابساته، فقديما كانت العلاقات الاجتماعية من البساطة بحيث كان الفرد يجد من أسرته ومن أقربائه من يعوضه عما فقده من علاقات خاصة ومن يقوم على رعايته إذا لزم الأمر. أما فيا الآن وبعد التطور الحضاري الصناعي الذي يعيش فيه، فقد تغير

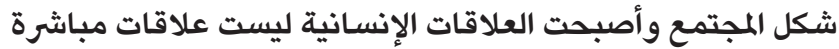
أولية كما كانت بل أصبحت من التعقيد بحيث لا يجد كبير السن من أفراد الأسرة من يتفرغ لخدمته أو يسهر على راحته، وأصبح

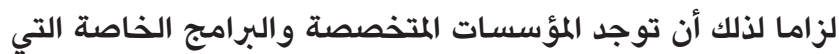

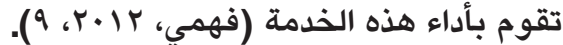

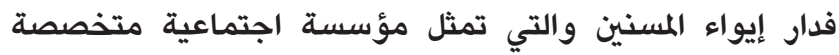
لرعاية المسنين من النوعين الذكور والإناث لتقديم أوجه الرعاية الصحية والنفسية والاجتماعية والدينية والترويحية والثقافية.

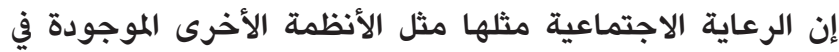
المجتمع، التي مرت بمراحل تطور مختلفة حتى وصلت إلى ما وصلت إليه اليوم، والتي أخذت الاتجاه العلمي وتستخدم الأسلوب إلول العلمي لتحديد الاحتياجات وحل المشكلات وتقديم أوجه الرعاية المختلفة وتقييمها من أجل تجويد خدمات الرعاية المقدمة للمسنين، ومن هنا تبرز أهمية هذه الدراسة في تقييم أوجه الرعاية المقدمة للمسنين ومستوى رضاهم. ومما لا شك فيه أن أساليب الرعاية بالمسن تتباين من مجتمع إلى أخر.

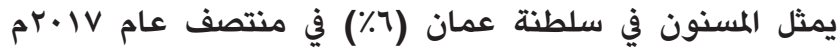

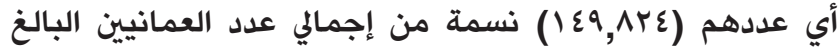

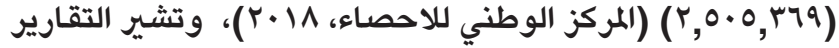
إلى أنه توجد دار وحيدة من نوعها في سلطنة عمان لإيواء المسنين معدومي الأقارب ووفق شروط وضعتها الدار، وتقدم خدماتها للمسنين عبر وزارة التنمية الاجتماعية، كما تتكفل الوزارة بتقديم خدمات متنوعة للمسنين حتى الذين لا يقطنون الدار مثل: صرف أجهزة تعويضية للمعوقين من المسنين، والرعاية المنزلية للمسنين

وغيرها من الخدمات (وزارة التنمية الاجتماعية، 7 ( • (Y). وأوضح دار الرعاية الاجتماعية الوحيد من نوعه في السلطنة

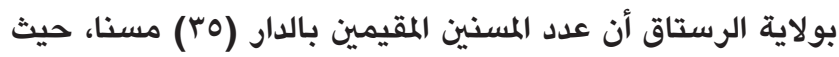

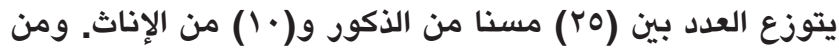

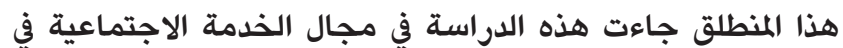
مجال المسنين للكشف عن خدمات الرعاية الاجتماعية المقدمة

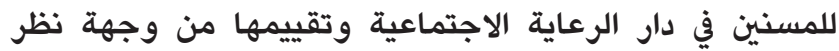

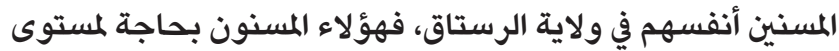
خاص من الرعاية التي نحاول أن نصل إلى مستوى المجتمعات المتقدمة. وتتبلور مشكلة البحث في التساؤلات التالية:

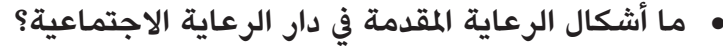
• ما مدى رضى المسن من الخدمات المقدمة في دار الرعاية

الاجتماعية؟ • ما مدى كفاية البرامج والخطط المقدمة لرعاية المسن في دور

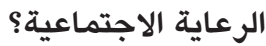

أولا: مشكلة البحث

إن نمو الفرد يتكامل في مرحلة الشيخوخة، ثم ينحدر تدريجيا في

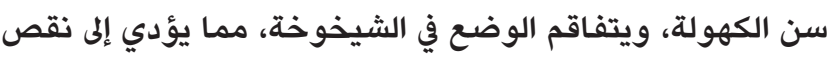
كفاءة الفرد وظهور تغيرات فسيولوجية واجتماعية ونفسية ولية

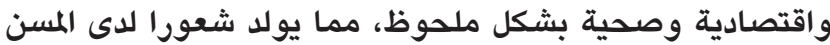

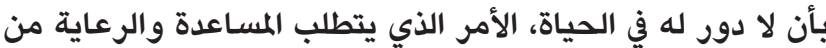
قبل الآخرين.

ولقد أكدت الاتجاهـات الحديثة في مجال رعاية المسنين على ضرورة الاهتمام بتلك المرحلة والنظر إلى مرحلة الشيخوخة باعتبارها إحدى مراحل النمو التي يجب التخطيط لها وتلبية الحاجات الخاصة بها، وقد تطور هذا الاهتمام عندما ظهر علم جديد مستقل يسمى علم الشيخوخة للالالة على الدراسات العلمية لظاهرة الشيخوخة. ويمثل الاهتمام بدارسة فئة المسنين وتوفير الرعاية لهم جانبا من جوانب الاعتناء بالثروة البشرية، إذ أن إن الن رقي المجتمع يقاس بمدى اهتمامه بالشيخوخة والمسنين خاصة في هذا العصر الذي نصرص فيه على تجميع كل الطاقات البشرية وحشدها في سبيل البناء، حيث تقف مسألة الاهتمام بالمسنين ضمن موضوعات الساعة التي يجب أن تستدعي انتباه المسئولين

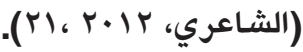
وجدير بالذكر أن المسنين بحاجة إلى ألوان متعددة من الرعاية توفر لهم الأمن والاستقرار وتشعرهم بأنهم كيانات مهمة في المجتمع وفي الأسرة وهذه الرعاية قد تكون في بعض الأحيان صحية وفي والي أحيان أخرى نفسية كما قد تكون اجتماعية أو اقتصادية أو دينية

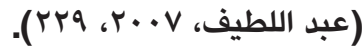
وكما أن للمسنين حاجات رئيسة يجب إشباعها مثل (الحاجة

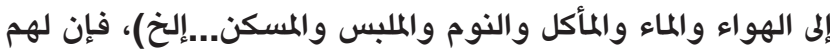
حاجات نوعية مثل: الحاجة إلى المحافظة على الطاقة، الحاجة إلى المحافظة على الروح المعنوية، والرغبة في الحياة، والحاجة إلى الى إلى الانتماء إلى الجماعات و ليس الشعور بالوحدة، كما أثبتت العديد من الأبحاث أن المسن يحتاج إلى: إشعاره بقيمته وأنه عضو نافع وليس مجرد كم، وتوفير الرعاية الصحية والنفسية والجسدية الصناية له، وتوفير قدر من الاهتمام بالمسنين و إنشاء نوادي و دور خاصة

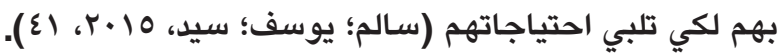
وقد اهتمت الدراسات في الدول التي لا تقوم بها الأسرة بـإسكان مسنيها ضمن وحداتهم السكنية ويميل فيها المسنون إلى الاستقلال بحياتهم المعيشية بالبحث عن بدائل في المؤسسات الإيوائية التي تعتبر ولاشك أقل الحلول نجاحا في توفير الرعاية والكرامة والاستقلال للمسنين، ففي مثل هذه المجتمعات وجد أن من بين البدائل عمل جيرات سكنية في مناطق الإسكان أو إقامة المناطق مأقل للإسكان التي تقدم حماية خاصة للظروف المعيشية لنوعية إعداد وجبات غذائية للمنازل أو تسهيلات كخدمات الكافيتريا وكذلك

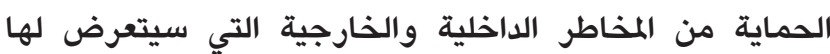
المسنين عن طريق الحراسة وخدمات الهاتف ومراكز الإسعاف...

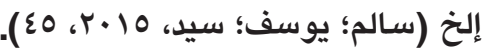
والواقع أن هذه الرعاية إنما تفرضها الآن ظروف العصر 
سنة فأكثر من المقيمين في دار الرعاية الاجتماعية للمسنين ولديه القدرة على التجاوب مع أداة الدراسة.

ك. الرعاية الاجتماعية (social welfare) تعرف الرعاية الاجتماعية أنها: "مجموعة البرامج والهاعية الهيئات

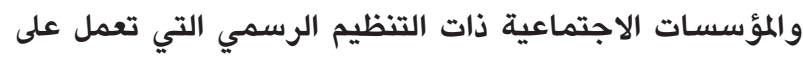

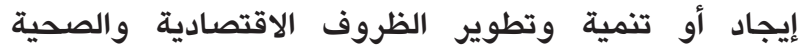

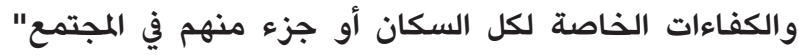

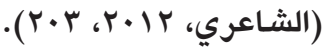

ويقصد بالرعاية الاجتماعية في الدراسة الحالية هي الخدمات

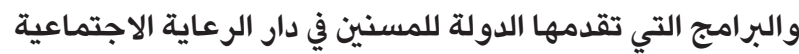
بالرستاق منها الرعاية الصحية والنفسية والدينية والترويحية

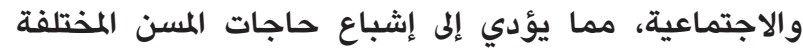
وصولا للرفاهية الاجتماعية بالدار.

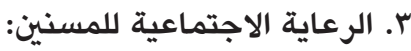
يقصد بها: المعاملة الطيبة لكبير السن في الأسرة، واتجاهات

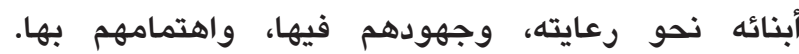

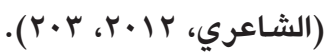

ويقصد بالرعاية الاجتماعية بالمسن في الدراسة المزمع إجراؤها بأنها المعاملة الطيبة التي تقدمها دالية دار الرعاية الراية الاجتماعية

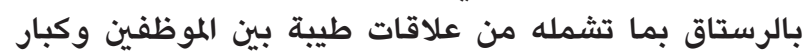

السن والخدمات التي يقدمها الدوار وموظفيه للمسنين.

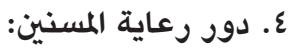
تعرف على أنها: "مؤسسة اجتماعية تخصصت في رعاية فئة من فئات المجتمع "كبار السن" من الجنسين تقدم لهم كافة

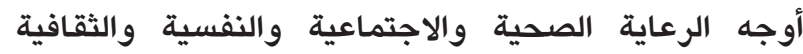
والترويحية، وقد تكون مؤسسة حكومية أو أهلية أو شبه الوالها

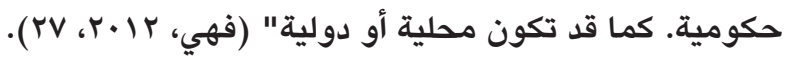
وتقصد الباحثة بدار رعاية المسنين في الدراسة الحالية هي مؤسسة حكومية خصصت لرعاية كبار السن من الجنسين

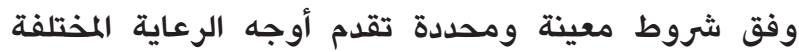
الصحية والنفسية والاجتماعية والدينية والترويحية.

$$
\text { أنواع الرعاية التي تقدم للمسنين: }
$$
يحتاج المسنون إلى تلقي الرعاية المناسبة التي تلائم ظروفهم المانية وحاجاتهم نظرا لطبيعة المرحلة التي يمرون بها وما لتحا تحدثه من

$$
\text { تغيرات وهي على النحو التالي: }
$$

أولا: الرعاية الصحية للمسنين: تعتبر على قمة أوجه الرعاية المقدمة لفة المسنين، وذلك لأن المان مثل

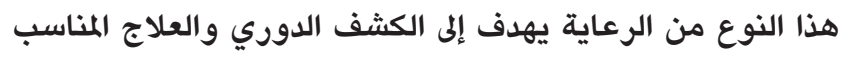

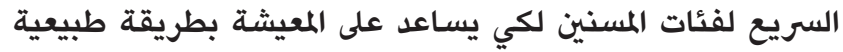

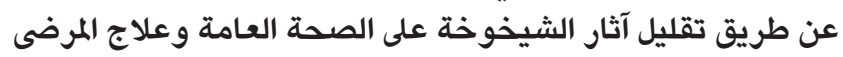

ثانيا: أهمية الدراسة

إ- الأهمية النظرية للدراسة • ت التجلى أهمية الدراسة بأن المسنين فئة من أفراد المجتمع، أمضوا

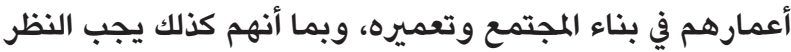

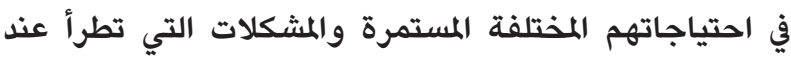

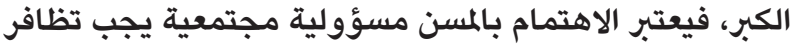
الجهود لتقييم برامج وخدمات الرعاية الاجتماعية المقدمة في

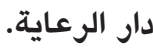

• تتجاوز أهمية الموضوع إلى الأهمية المجتمعية للتوصل إلى نتائج وتوصيات للرقي بمستوى الخدمات المقدمة للمسن في دور إلمعيه الرعاية مما يسهم في عملية التخطيط والتنمية. • تقودنا الدراسة للكشف عن الاحتياجات الجديدة والمتزايدة للمسن العماني في الوقت الراهن باعتبار أن الاحتياجات متجددة ومستمرة ومتفيرة.

r- الأهمية التطبيقية للدراسة:

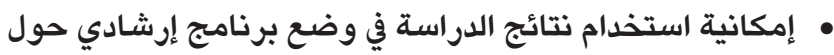

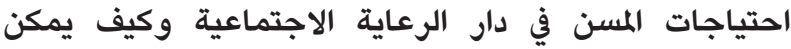

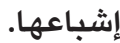

• وضع نتائج الدراسة ومقترحاتها بين يدي وزارة التنمية الاجتماعية ودار الرعاية الاجتماعية بولاية الرستاق.

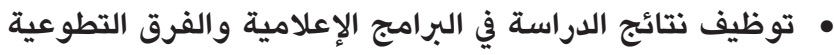
المرتبطة بالمسن لإمكانية تقديم أفضل رعاية الاعلامية ممكنة للمسن.

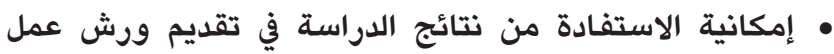

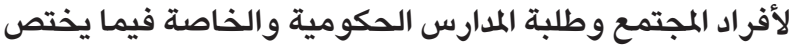

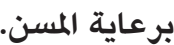
• يمكن الاستفادة من نتائج الدراسة في توزيع النشرات

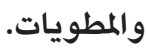

ثالثا: أهداف الدراسة • تحديد أشكال الرعاية المقدمة في دار الرعاية الاجتماعية. • تحديد مدى رضى المسن من الخدمات المقدمة في دار الرعاية الاجتماعية • تقييم مدى كفاية البرامج والخطط المقدمة لرعاية المسن في الإية

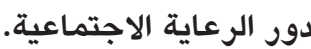
رابعا: المفاهيم المرتبطة بالدراسة ترتبط بهذه الدراسة العديد من المفاهيم من أهمها ما يلي:

1. المسن (The Elderly)

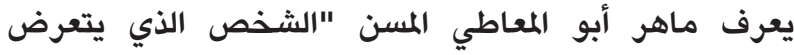

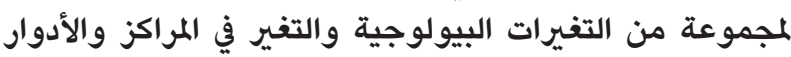

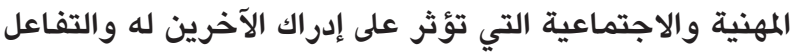
معه بصورة تنعكس على تصور المسن لذاته وسلوكه" (أبو الأورين

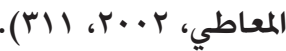
ويقصد بالمسن في الدراسة الحالية كل ذكر أو أنثى بلغ ستين 
بالعزلة في المجتمع وقد يتمتع الكثيرون منهم بالخبرات والمهارات والقدرات التي تمكنهم من الاستمرار في أداء دورهم في المجتمع.

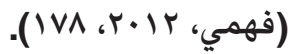
وفي مصر أجريت دراسة قام بها محمد نبيل عبد الحميد عن العلاقات الأسرية للمسنين وتوافقهم على معيشة كبار السن مع دماته

أبنائهم توفر لهم عدة مقومات هي: - - الاحتفاظ بالمكانة الاجتماعية.

- - الاحتفاظ بالعلاقات الودودة.

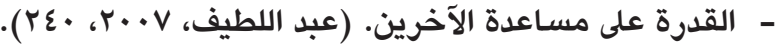

ثالثا: الرعاية النفسية للمسنين: إن رعاية المسنين نفسيا تتطلب جهودا كبيرة من أجل تقديم الرعاية النفسية على أكمل وجه، وتتطلب مهارة فائقة، وهذا ما يستلزم وجود الأخصائي النفسي مع الأخصائي الاجتماعي.

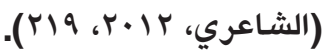

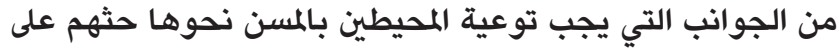
تجنب المناقشات التي تعمل على إثارة أعصابه أو تضعه في موضع

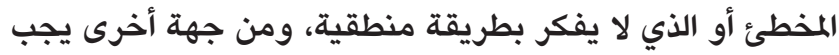
عدم تخطي الشيخ فيما يقول بقدر الإمكان، وذلك لأن التخطي

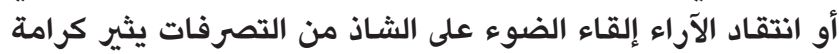
المسن ويدفع به إلى مقابلة الهجوم بهجوم مضاد عنيف. (فهمي،

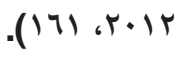
وغني عن القول إنه يجب أن يستأصل من الجو الاجتماعي المحيط

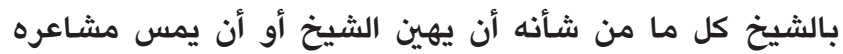
بالاستهزاء بما يقول أو بما يعمل، أو ما يثير حفيظته أو يغيظه الته

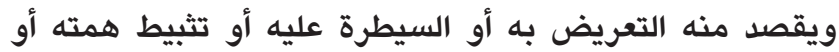

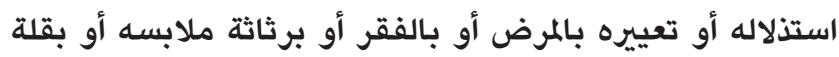

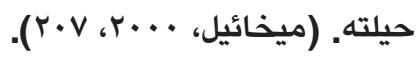

رابعا: الرعاية الدينية والثقافية للمسنين: تهدف هذه الرعاية إلى تزويد المسنين بقدر مناسب من الناحية

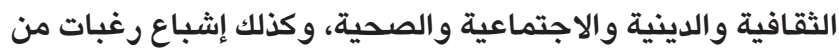
لديهم ميول للمطالعة وشغل وقت الفراغ بالاطلاع، ويتم توضيح

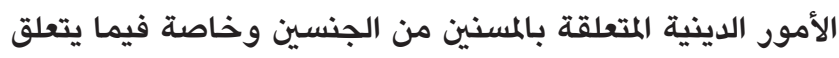
بأمور العبادات، ويتم كل ذلك عن طريق النقاش والحوار بين

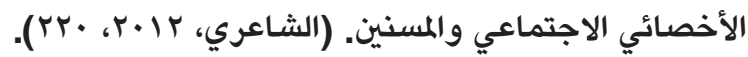

ومن أسـاليب رعاية المسنين في ضوء التصور الإسلامي: أولا: الأساليب الوقائية: التيائ رعايه

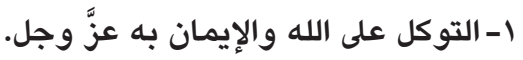

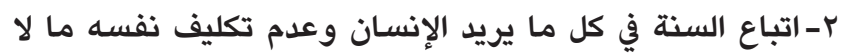

\section{يطيق من عمل.}

r-عمل الطاعات والإكثار منها وخاصة بر الوالدين فقد ورد أن العقوق دين.

ع- حفظ القرآن الكريم و العمل به وقراءته والتمعن، ولا شك أن قارئ القرآن يحفظه الله من الهرم والعجز الكرئ والكمل وفله واعله
بقدر الإمكان، وعلى هذا الأسـاس يجب توافر عدد كبير من الأطباء المختصين بأمراض الشيخوخة، وكذلك توفر عدد من المختصين

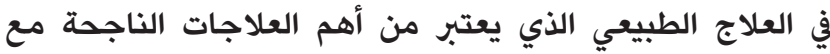
المسنين، وأوجه الرعاية الصحية للمسنين عن طريق الآتي: الفحص الشامل الدوري، العلاج الطبي، التأهيل الطبي الشامل، الشئ،

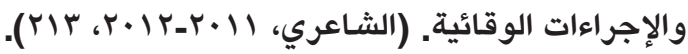
ويحتاج المسن إلى كشف دوري للعيون وحالات الرمد، وتقدم سماعات طبية لمن يعانون من ضعف السمع، ويمكن أن يحصل

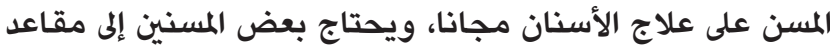

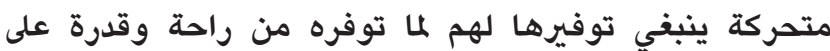

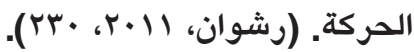
والواقع أن الرعاية الصحية في مرحلة كبر السن ترتكز على أسـاسين: ا - الأسـاس العلاجي ويتضمن تخليص المسن من الشوائب الصحية

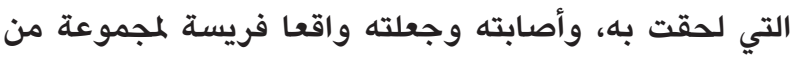

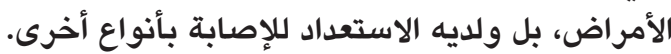

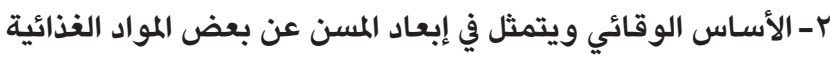
الضارة بحالته والتدريب على ممارسة بعض الأنشطة الجسمية كالمشي مثلا وذلك حتى لا تكون عرضة للإصابة بأمراض

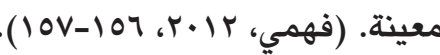
الشيخوخة لا تستلزم بالضرورة الإصابة بالأمراض التي تشيع

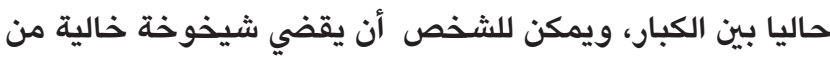
الأمراض التي قد يعاني منها المسنين، ومن الأفضل أن تسمى هذه الأمراض بالأمراض المصاحبة للشيخوخة حتى لاض لا يفهم أن ارتباط

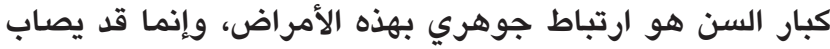

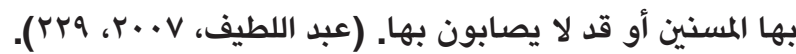
ثانيا: الرعاية الاجتماعية للمسنين: الرعاية الاجتماعية تشتمل على ثلاثة جوانب هي: الجانب الوقائي، والجانب العلاجي، والجانب التنموي، وفي مجال رعاية المسنين

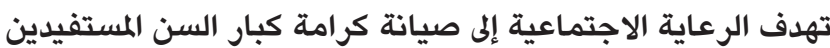
من هذه الرعاية، وذلك بتقوية الروابط الاجتماعية، والشعور بالانتماء لهم، كما أنها تهدف وإلى تنمية الوازع الديني والخلقي

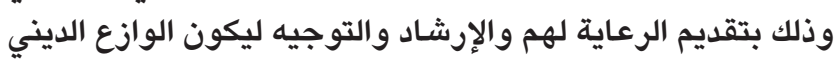
خير ضمان لاستمرارية وديناميكية الرعاية. ويمكن أن نورد بعض النقاط المهمة للرعاية الاجتماعية لمجال

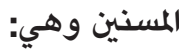
ا- توفير المناخ الاجتماعي المناسب الذي يؤدي إلى تعويض الفئات

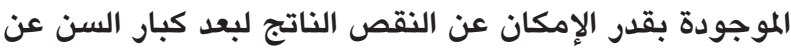

$$
\text { أسرهم الطبيعية. }
$$

r-مساعدة المسنات على التكيف مع البيئة وتنظيم البرامج والأنشطة لاكتشاف ميولهن وشغل أوقات فراغهن. r-العمل على توثيق الصلة بين المسنين وأسرهم وتذليل كافة

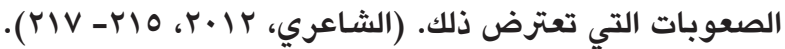

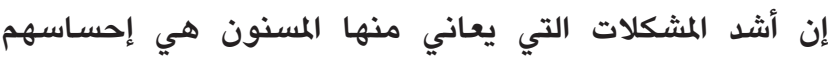




$$
\begin{aligned}
& \text { الموجهة للمسنين . } \\
& \text { r. الرعاية المنزلية للمسنين. } \\
& \text { r- مشروع جلساء المسنين }
\end{aligned}
$$

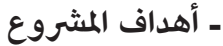

ا ـ توفير البيئة الأمنة والمناسبة لرعاية المسنين .

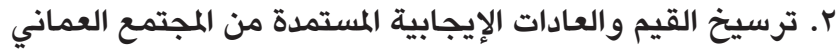

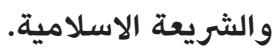
r. تحقيق الاستقرار الصحي والنفسي والاجتماعي للمسنين من خلال العناية الصحية المنزلية من قبل جلساء مختصين.

ع. التقليل من المخاطر الناجمة من العمالة الواخدة . ๑. مساعدة المرأة العمانية للإنخراط في سوق العمله من العمل من خلال تدرييها وتأهيلها لتحسين الوضع الاقتصادي والمعيشي لها لـانيه r- التوجه إلى تحويل المجالس العامة السبل إلى نوادي للمسنين: يتمثل هذا الدعم الذي تقدمه الوزارة في تشجيع الأهالي على بناء المجالس العامة والتي تعرف باسم السبل من خلال تقديم الدعم المالي لتنفيذ هذه المشاريع والتي تعتبر بمثابة نوادي اجتماعية

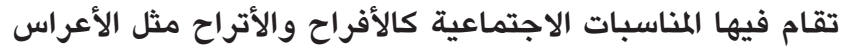

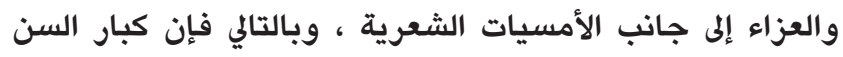
يعتبوون من مرتادي هذه المجالس والمشاركين فيها من خلال نقل خبراتهم في مجالات الحياة المختلفة ، أيضا تستخدم السبل من قبل كبار السن في تحفيظ القرآن الكريم للأبناء ، كما إنها

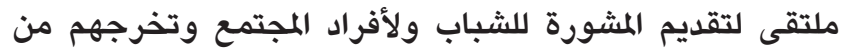
العزلة والانطواء وتثري دورهم في المجتمع .

ع- البرنامج الوطني للرعاية المنزلية للمسنين: تقدم الوزارة برنامج الرعاية المنزلية للمسنين بالتعاون والتكامل مع وزارة

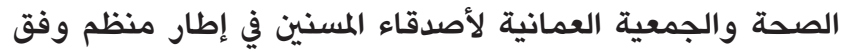
آليات عمل معتمدة ومحددة وفقا لاختصاص كل جهة . وتتولى وزارة التنمية الاجتماعية تقديم الخدمات الاجتماعية

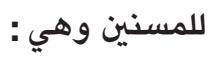

ا ـ تقديم وسائل الدعم الحياتي ( الأجهزة والمعينات ) .

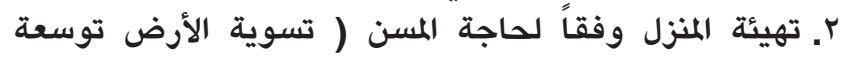
المداخل ... الخ ) متهنه r. الدعم المادي ( معاش الضمان الاجتماعي _ المسـاعدة المقطوعة )

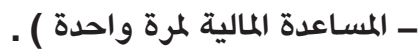

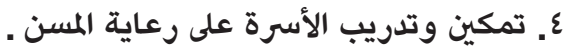
○. توفير الجليس / الأسرة البديلة . 7. توجيه وإرشاد الأسر اجتماعيا ونفسياً. V. تنسيق جهود المجتمع المحلي (موقع وزارة التنمية الاجتماعية).

دار الرعاية الاجتماعية بالرستاق ( نموذجا): تعتبر دار الرعاية الاجتماعية بالرستاق بمحافظة جنوب الباطنة هي المؤسسة الوحيدة على مستوى السلطنة التي تأوي نزلاء من مختلف المحافظات و الولايات.
๑- دعاء الله تعالى والتعوذ من الهرم وسوء الخاتمة. 7- كثرة الصدقة والعطف على المساكين.

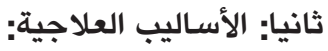
ا- إسقاط بعض التكاليف التي لا يستطيع القيام بها وهذا دليل على إشفاقه على المسن ومراعاة لسنه وحاله. r- حث المجتمع على احترام الكبير وتوقير الصغير.

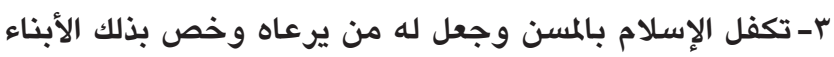

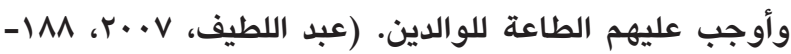

ع- تخفيف الشريعة الإسلامية على المسن ومنحه المزيد من الرخص

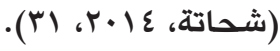

خامسا: الرعاية الترويحية للمسنين: الخدمة الترويحية أسلوب يمكن أن يساعد المسنين على استثمار

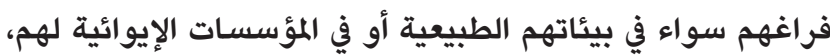
ويلاحظ أن كثيرا من الأفراد يتركون بعد التقاعد ويهملون،

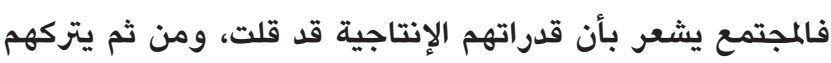

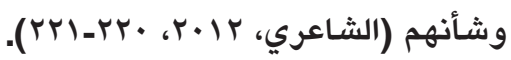
والشخص الذي يعمل في مجال الترويح لابد أن يلم بمجموعة من

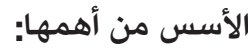
- الحاجة إلى الإلمام ببعض الجها: الجوانب المتصلة بعملية التقدم في

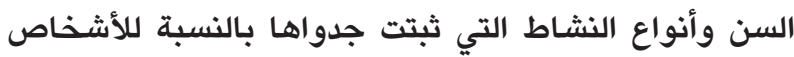

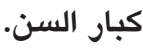
- طرق وأدوات تنظيم النشاط الترويحي ومناسبتها للأشخاص

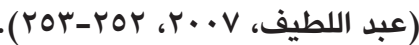

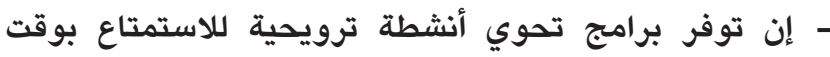
الفراغ للمسنين هي مسؤولية المجتمع والأندية والجمعيات والمؤسسات العامة والخاصة وغيرها. هناك اعتقاد خاطئ بأن الكبار والمسنين لا يحتاجون التوجيه لأنشطة ترويحية متعددة فهم قادرون على الاهتمام شخصيا بمتطلباتهم واحتياجاتهم نحو الأنشطة التي تمارس أثناء وقت الفراغاغ الاهن وفي الواقع أن غالبية الكبار المسنين لم تهيأ لهم الفرص لتعلم كيفية استثمار

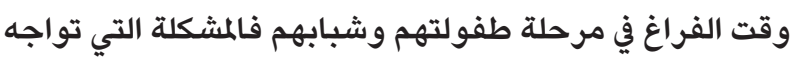

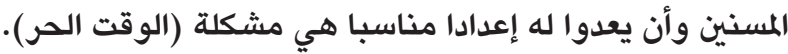

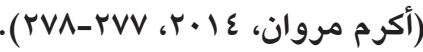

الرعاية الاجتماعية للمسنين في سلطنة عمان: الخدمات المقدمة للمسنين

ا- برنامج تقدير: قيام المؤسسات الحكومية وغير الحكومية والمجتمع بتقديم الرعاية الاجتماعية والصحية والنفسية

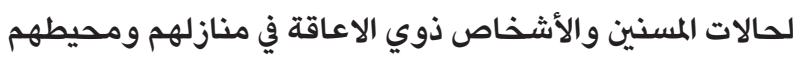

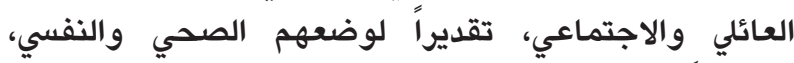

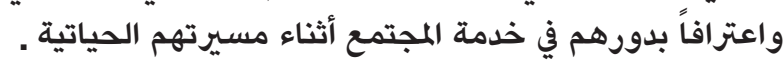

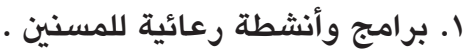
r. توجيه المجتمع وحثهم على المشاركة في البرامج والأنشطة وعائة لئن 


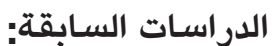

تتعدد الدراسات والأطر النظرية لدراسة هذا الموضوع، وقد تم تناول الدراسة من قبل باحثين مختلفين يمكن الاستفادة منها. وفيما يلي عرض بعض الدراسات ذات الصلة بدراستنا هذه.

أولا: الدراسات العربية

ا- دراسة (السعوي، 17+ץ) بعنوان "رعاية المسنين في دور الرعاية الإيوائية بمنطقة القصيم: دراسة تحليلية لواقع رعاية المسنين في القطاعين الخاص والأهلي.

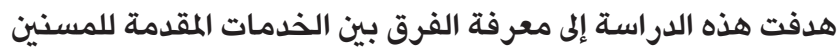
المقيمين في الدور الإيوائية الحكومية، والخدمات المقدمة للمسنين المقيمين في الدور الأهلية، وذلك من خلائل الإل دراسة الواقع الذية والئ تعيشه، والخدمات التي يقدمها كل من مراكز الرعاية الاجتماعية للمسنين في عنيزة وهي مؤسسة حكومية تابعة لوزارة الشؤون

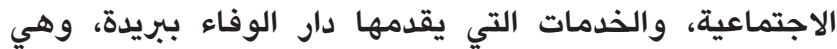

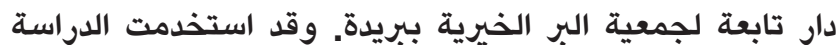
منهج المسح الاجتماعي بأسلوب الحصر الشامل، من خلابلة خلال المقابلة لكامل مجتمع الدراسة من المسنين أنفسهم والموظفينين.

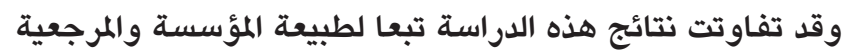
التابعة لها، وتبين وجود قصور في المؤسسات الإيوائية الأهلية للمسنين منه أكبر من المؤسسات الإيوائية الحكومية خاصدة في في الإنية مجالات: محدودية الوقت المسموح به للإقامة، وتدني مستوى الإن

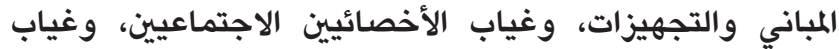

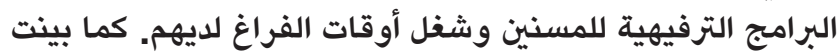

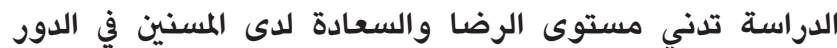
الإيوائية الأهلية مقارنة بالمسنين في الدور الإيوائية الحكومية.

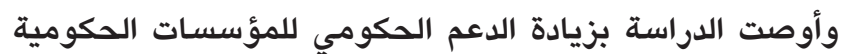
التي تعنى بالمسنين، وفتح المزيد من الدور الإيوائية الحكومية في

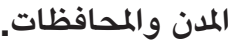

r- دراسة (الصواعي، 10+r) بعنوان "مؤشرات تخطيطية لتطوير خدمات الرعاية الاجتماعية للمسنين في المجتمع العماني

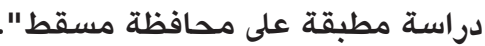
هدفت الدراسة إلى التوصل لمؤشرات تخطيطية تساهم في تطوير

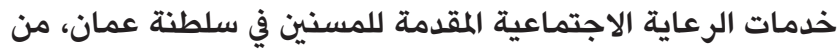
خلال التعرف على الخدمات المقدمة للمسنين، وأبرز احتياجاتهمان الماني،

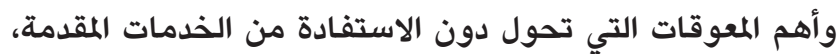

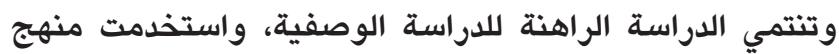

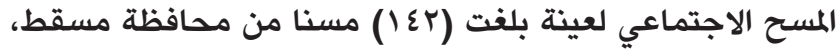

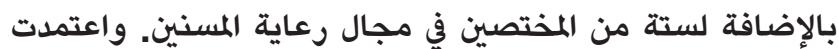
الدراسة على صحيفة الاستبار للمسنين، ودليل المقابلة للمختصين من إعداد الباحثة. توصلت الدراسة لعدد من المؤشرات التخطيطية أبرزها: الحاجة للتوسع في تقديم الخدمات المتنوعة لوعادية الماية المسنين

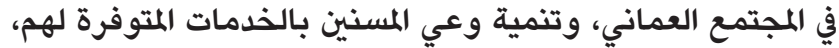
وتحسين آليات الإعلان عن الخدمات المقدمة للمسنين، وتطوير

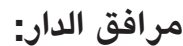

تضم دار الرعاية الاجتماعية بالرستاق التابعة لدائرة التنمية الاجتماعية عددًا من المرافق الإدارية والخدمية منها:

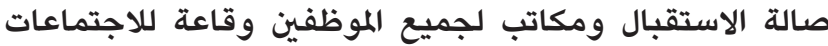
وأخرى للاحتفالات تقام فيها الفعاليات ومجلس استقبال الضيوف، كما تضم الدار عيادة تتكون من صالة استقبال وصيدلية طبية وصالة العلاج الطبيعي ومكاتب للطبيب وأخرى تضاري

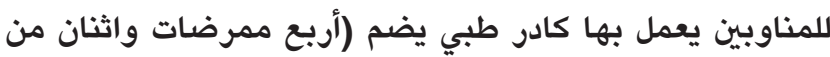

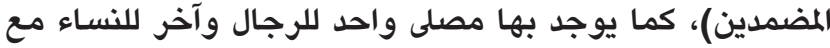
أماكن مخصصة للوضوء ودورات مياه للمصلين. وتشتمل الدار على (') وحدة سكنية كل وحدة تضم أربع غرف ثلاث منهن

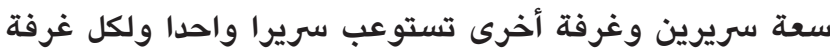

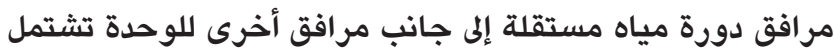
(دورة مياه عامة وصالة ومطبخ صغير) مجهزات بأجهزة التكييف والتبريد والتلفاز وتستوعب الوحدة سبعة أشخاص بينما

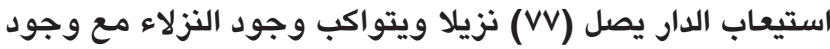

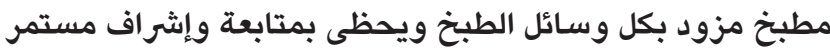

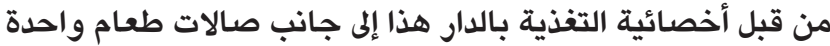
للرجال وأخرى للنساء ذات مساحة واسعة.

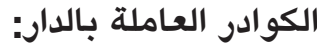
يعمل بالدار (ro) موظفا حكوميا يقومون بالعمل في عدد الإد من الوظائف والتخصصات منهم الإداريون والأخصائيون الاجتماعيون والنفسيون وبرامج التوعية والتغذية إلى جانب

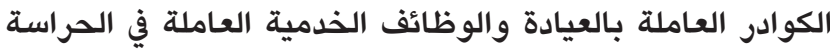
والسائقين وغيرها من الكوادر وجميعهم يخضعون تحت إثراف (رئيس قسم الدار).

هذا ويتم تقديم جميع الخدمات للنزلاء المتمثلة في النظافة الشخصية والعامة والتغذية والعلاج وغير هـا.

مناشط وأنشطة الجمعية: تقوم الدار إلى جانب الأعمال المناطة بها في تنفيذ عدد من الفعاليات بالتعاون مع الجهات الحكومية والخاصة والفرق التطوعية والجمعيات الأهلية ومن مناشط الدار:

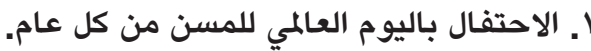

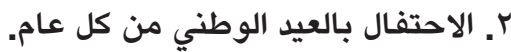
r. تنفيذ وجبة إفطار جماعية في شهر رمضان. ع.تنفيذ ندوات ومحاضرات ودروس عمل متنوعة للنزلاء

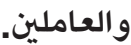
0. تنفيذ رحلات ترفيهة للنزلاء في المواقع السياحية. 7. استقبال الزوار من داخل وخارج السلطنة. V. تنفيذ فعاليات مشتركة مع الجامعات والكليات والمعاهد وغيرها من المؤسسات وجمعيات المرأة 
والمراكز الصحية، بينما أوضحت النتائج أن عدم اهتمام وتعاون

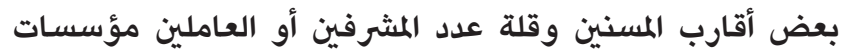

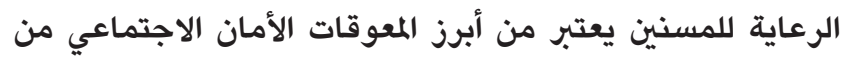

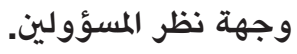

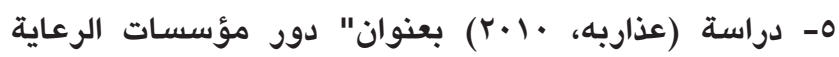

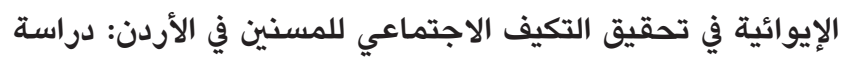

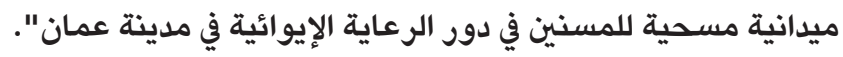
هدفت الدراسة التعرف على دور مؤسسات الرعاية الإيوائية في الرئ

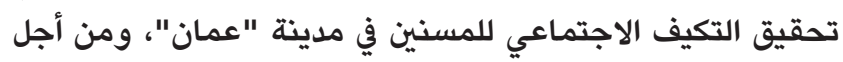

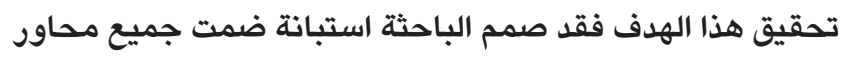

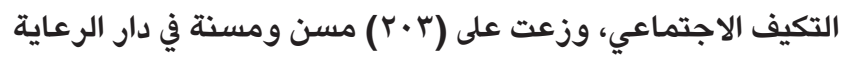

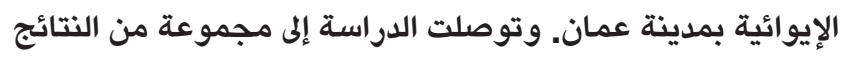

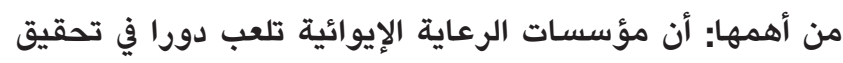

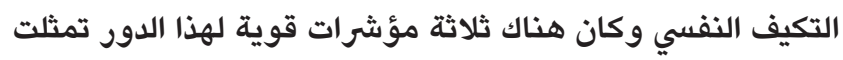

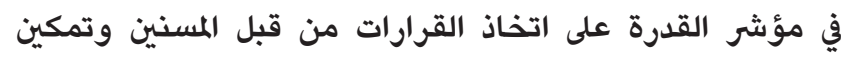

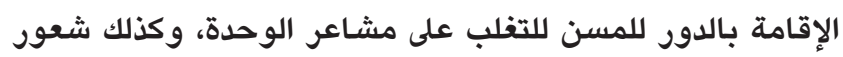

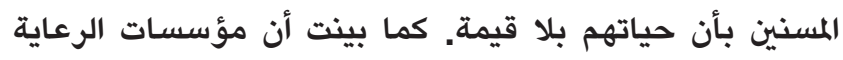

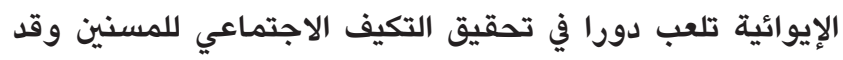

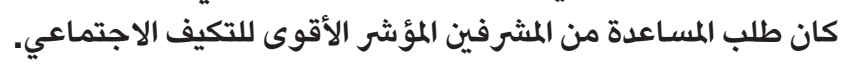

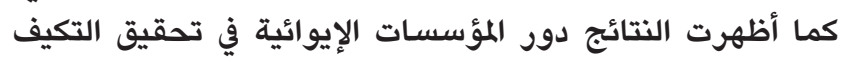

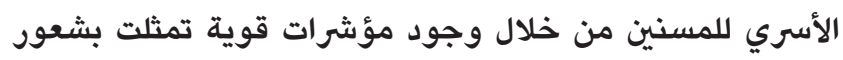

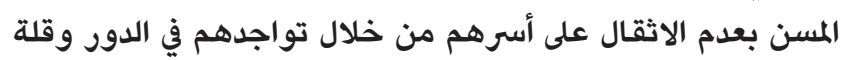

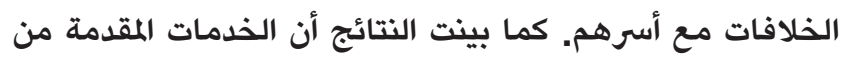

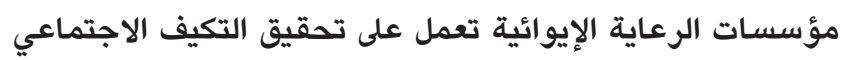

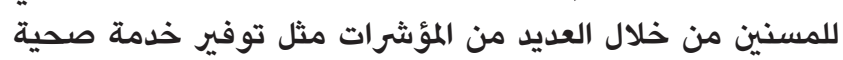

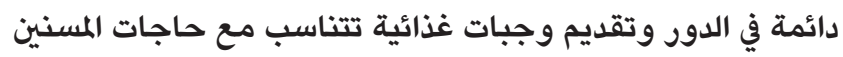

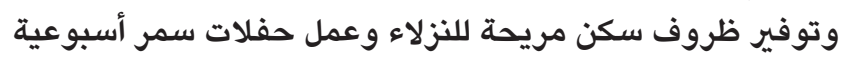

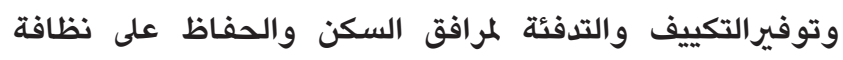

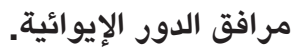

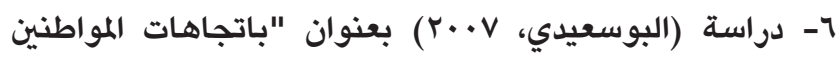

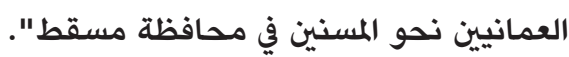
تأكيد عينة الدراسة على أهمية الرعاية الأسرية للمسنين وبين

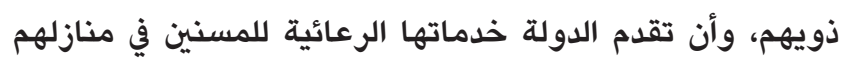

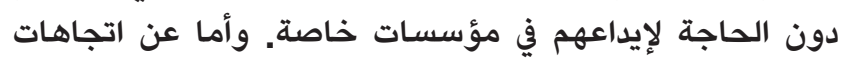

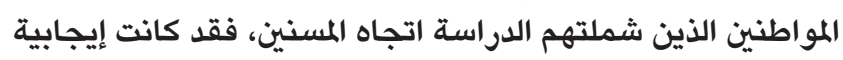

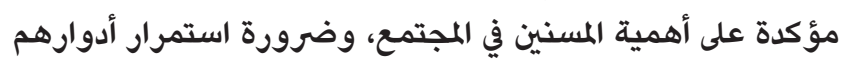

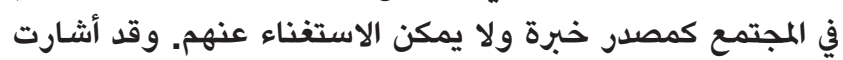

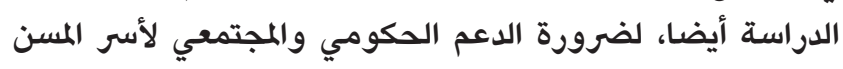

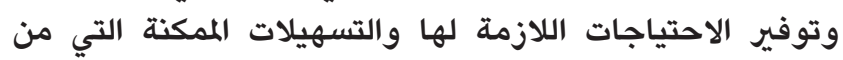

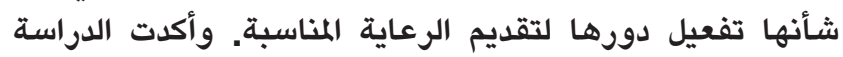

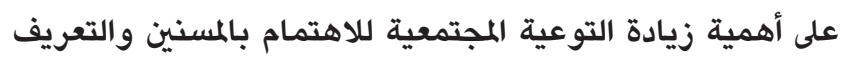
باحتياجاتهم ومشكلاتهم وكيفية التعامل معهم.

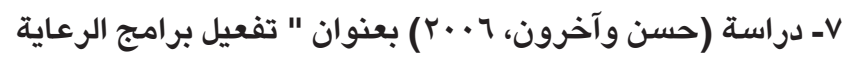

آليات المتابعة والتقييم للخدمات التي تقدمها مؤسسات رعاية

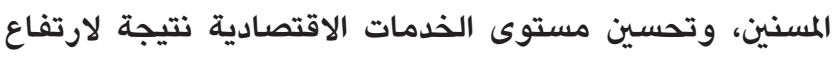

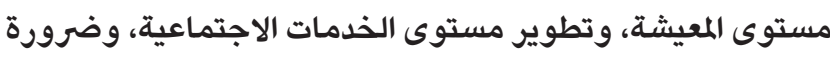
الاستعداد لمواجهة التغيرات المترتبة للتغير الاجتماعي ملتوي على الأسرة

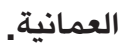
وانتهت الدراسة إلى بعض المقترحات والآليات التي يمكن أن تحسن

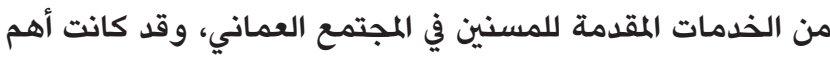

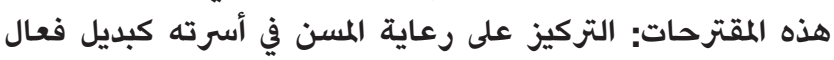

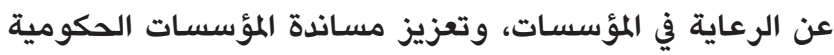
والأهلية للأسر التي ترعى المسنين، وتمكينها من رعايتهم على المانى

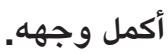

r- دراسة (العسكرية، 10 1 ب) بعنوان "الضغوط الحياتية والقلق والاكتئاب لدى عينة من المسنين بسلطنة عمان".

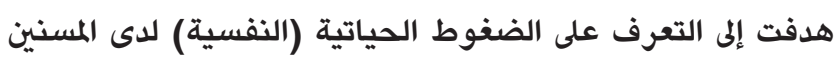

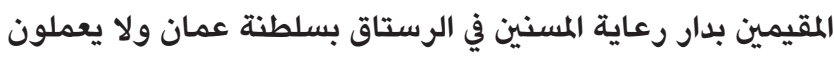

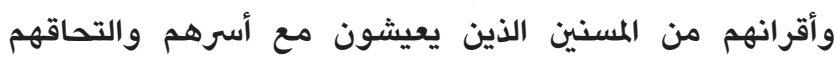

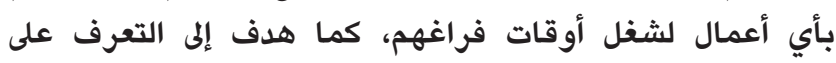

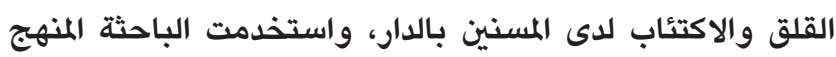

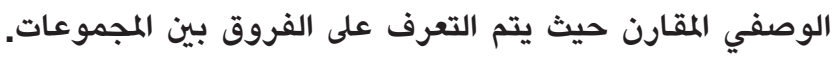

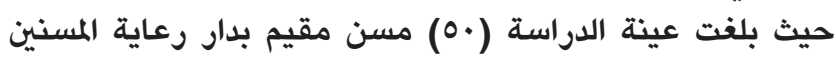

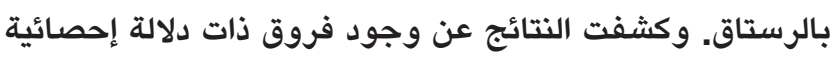

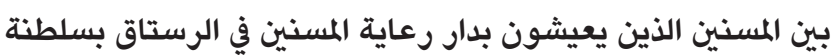

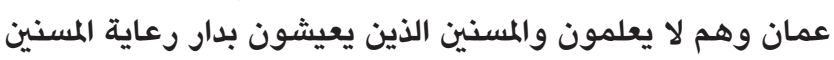

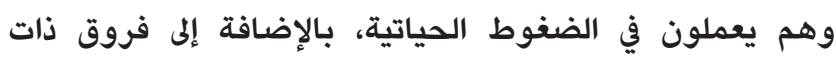

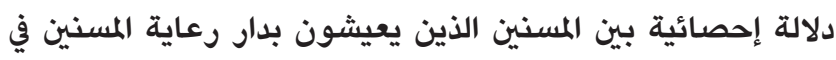

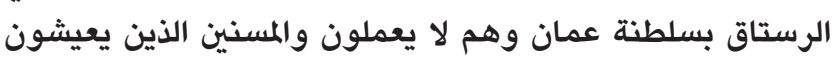

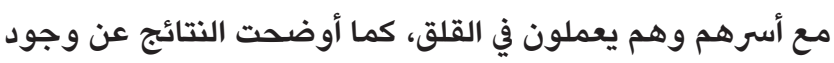

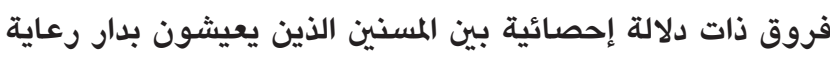

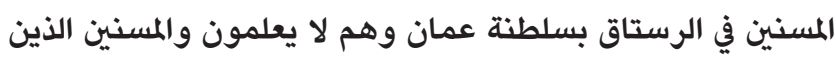
يعيشون مع أسرهم وهم يعلمون في الاكتئاب.

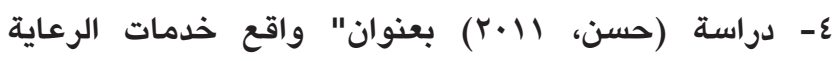

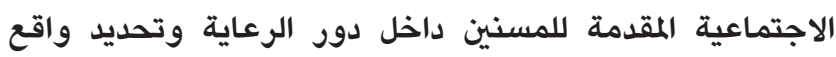

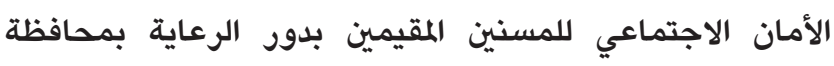

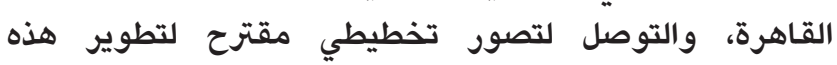

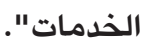

خلصت الدراسة إلى وجود علاقة ارتباطية ذات دلالة إحصائية بين

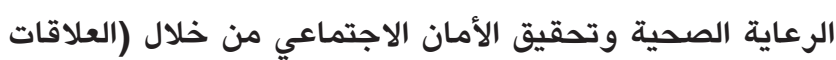

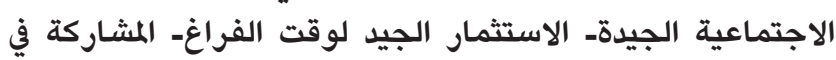

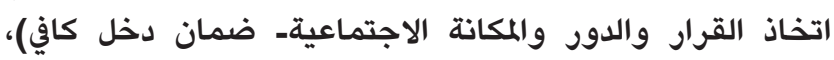

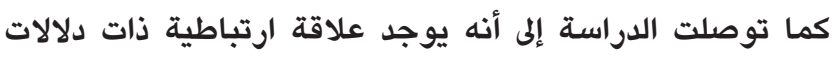

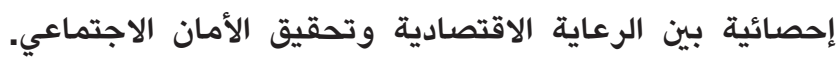

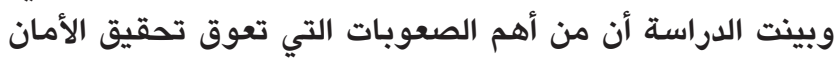

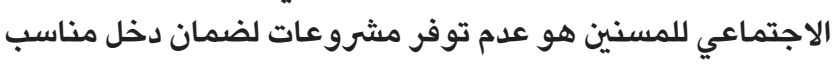
لهم. وكذلك عدم توفر وسيلة انتقال بين مراكز الرعاية النهارية 
وعدم وجود برامج جماعية تدعم العلاقات داخل الدار. هذا بالإضافة لانخفاض رضا المسنين عن أنفسهم ووجودهم في الدار. واقترحت الدراسة بعض المؤشرات التخطيطية كتدريب وتأهيل مقدمي الرعاية في الدار من العاملين فيها وإجراء تعديلات على العات العمات

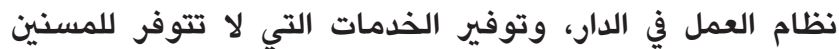
والأنشطة المرغوبة من قبل المسنين أنفسهم، ودعم علاقة الدار بالمسنين وأسرهم لضمان التواصل الدائم.

ثانيا: الدراسات الأجنبية اـ دراسة (Himes, 2001) عن كبار السن في الولايات المتحدة واختلاف الأعراق في عنايتهم بالمسنين وموقفهم منها حاولت معرفة الفروق في الرعاية الأسرية للمسنين بين مختلف العرقيات في المجتمع الأمريكي (البيض والأفارقة والمكسيكيون والآسيويون )، ووجدت أن المسنين الأفارقة يتلقون الرعاية

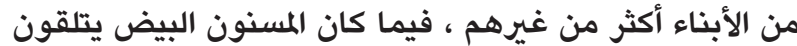

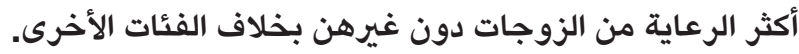
r- دراسة (Creanza and Mcwhirter, 2003) "دراسة العمل الجماعي وفاعليته في رفع مستوى الرعاية النفسية لدى الرى المسنين في دار الإيواء بولاية فرجينيا"، التي هدفت إلى التعرف

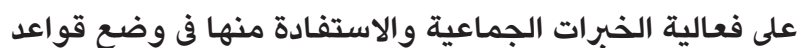
لأعمال جماعية مستقبلية. طبقت الدراسة على عينة مكونة

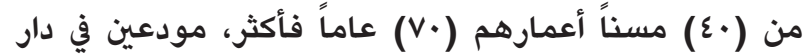

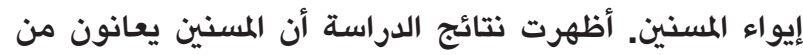
الاضطرابات النفسية أكثر من معاناتهم من الاضطرابات

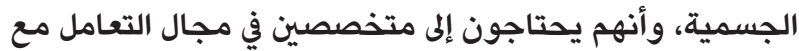
المسنين، وإلى مساندة أهليهم وذويهم أكثر من احتياجهم للمتخصصين. ولوحظ أن المسنين الذين يزورهم أبناؤهم أو أو أونئ أفراد أسرهم، كان لديهم نشاط وتفاؤل أكثر من غيرهم من ين

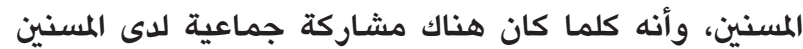
كان توافقهم النفسي أعلى. r- دراسة (Lecovich, 2004) بعنوان شبكات الدعم الاجتماعي في تخفيف الوحدة النفسية لدى كبار السن.

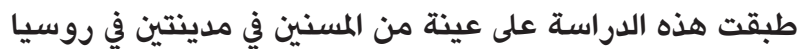

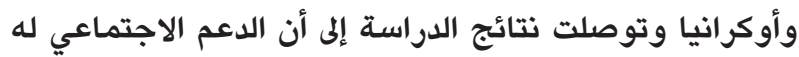

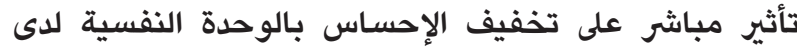

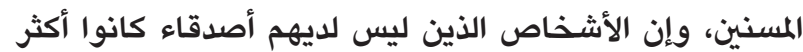

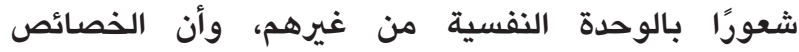
الاجتماعية وشبكة العلاقات الاجتماعية لها علاقة بالشعور

بالوحدة النفسية.

ع- دراسة (Nevin and Nurcan, 2006) بعنوان "تقييم تغذية كبار السن الذين يقيمون وحيدين ومع العائلة في دور الرعاية

في تركيا"

هدفت الدراسة إلى تقييم وضع التغذية لعينة من كبار السن في تركيا، وقد أجريت الدراسة على عينة مكونة من (وrqع) مسنا

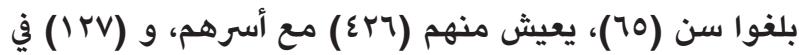

الاجتماعية المقدمة للمسنين في ضوء الممارسة العامة للخدمة

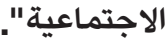

تسعى الدراسة إلى تحديد مدى إسهام برامج الرعاية الاجتماعية المقدمة للمسنين داخل مؤسسات الرعاية في إشباع احتياجاتهم

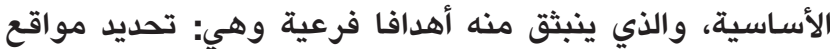

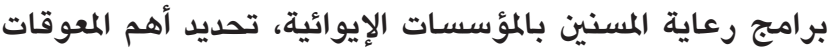
التي تؤثر على فاعلية برامج رعاية المسنين بالمؤسسات الإيوائية، والتوصل لتصور مقترح لإسهام الخدمة الاجتماعية من خلال نموذج الممارسة العامة في زيادة فاعلية برامج رعاية المسنين. اعتمدت الدراسة على منهج المسح الاجتماعي بالعينة للمسنين المقيمين بمؤسسات رعاية المسنين بمحافظة القاهرة، وعينة أخرى من خبراء من أساتذة الخدمة الاجتماعية، واستخدم الباحث استمارة قياس برامج الرعاية المقدمة للمسنين، ودليل مقابلة للخبراء. كشفت نتائج الدراسة أن هناك انخفاضا في مستوى الخدمات والبرامج الصحية والثقافية والدينية والترفيهية والاجتماعية المقدمة للمسنين داخل المؤسسات الإيوائية، كما اتضح أن هناك بعض الصعوبات الخاصة بالمسن والتي تؤثر بشكل واضح على فاعلية البرامج المقدمة لهم. كما أبدى الباحث تصورا مقترحا لإسهام الخدمة الاجتماعية في تقديم أفضل السبل لرعاية المسنين في ضوء الممارسة العامة للخدمة الاجتماعية.

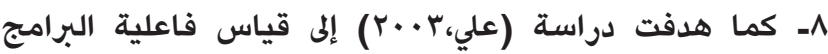
الترويحية في خدمة الجماعة وتحقيق التوافق الاجتماعي للمسنين بدور الإيواء بالبحرين. وقد أثبتت الدراسة فاعلية البرامج الترويحية وأكدت على أهميتها من خلال دورهـا في إكساب المسنين المهارات والخبرات الاجتماعية كالتعبير والضبط الانفعالي والحساسية الاجتماعية وتحقيق التوافق الاجتماعي. وأشارت الدراسة أيضا إلى حاجة المسن للمساعدة من الآخرين وخاصة في المواقف التي تتصف بالتوتر والانفعال والضغط الأمر الذي يتطلب تدريبه على الاسترخاء العقلي والعضلي والتدريب على أسلوب حل المشكلات. وأوضحت الدراسة أيضا فاعلية البرامج الترويحية في قدرتها على تعديل السلوك غير المرغوب اجتماعيا. وأشارت نتائج الدراسة إلى أبرز الأساليب التي ساهمت في إحداث التغيير الإيجابي للمسنين وهي أسلوب المحاضرة والمناقشة الجماعية.

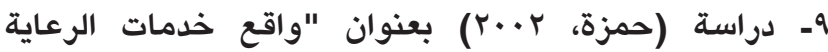
الاجتماعية للمسنين". جاءت لتسلط الضوء على الواقع الفعلي لخدمات وبرامج الرعاية الاجتماعية المقدمة في دور الرعاية الاجتماعية في مملكة البحرين، والتوصل لمجموعة من المؤشرات التخطيطية التي تساهم في رفع مستوى الخدمات والبرامج التي تقدمها دور رعاية المسنين. وأشـارت نتائج الدراسة إلى عدم رضا المسنين عن طرق التعامل

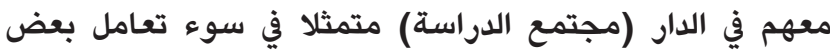
العاملين مع المسنين ممن تشملهم الدراسة، وعدم رضا المسنين عن الرعاية الاجتماعية التي يقدمها الدار نتيجة لجمود نظام العمل بالدار وعدم تجديد في البرامج وعدم مناسبتها للمسنين، 


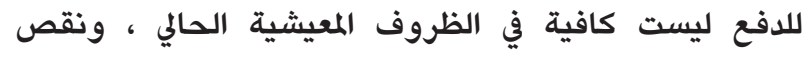
الحكومة في الميزانية ، وعدم السماح للوكالات الحكومية برعاية كبار السن ، لذلك يجب على الحكومة إنشاء إدارة للخدمة ودعم كبار السن بشكل أكبر وكذلك تدريب المسؤولين الحكوميين للحصول على مزيد من المعرفة حول كيفية رعاية كبار السن. بالإضافة إلى ذلك، يتعين على الحكومة تدريب ملئ المزيد

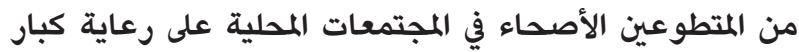
السن والمساعدة في نقلهم إلى المستشفيات.

9- دراسة (Freund \& Winterstein, 2017) والتي تهدف الدراسة إلى دراسة تجربة الأخصائيين الاجتماعين في تسهيل دمج العاملين في الرعاية المنزلية بغرض علاج كبار السن. تم استخدام المنهج النوعي باستخدام مقابلات شبه معمقة مع العابه ^ا أخصائي اجتماعي على اتصال يومي مع عملاء كبار السن. وقد أشارت النتائج وجود ثلاثة محاور رئيسية الحواجز

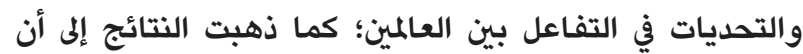
الأخصائيين الاجتماعين يلعبون دورًا رئيسيًا، حيث يعملون كجسر ثقافي في عملية تقديم الرعاية للمسنين ، كطريقة لتلبية احتياجات كبار السن المتطرفين وأسرهم.

التعقيب على الدراسـات السابقة: يتضح من خلال عرض الدراسـات السابقة تأكيدها على أهمية المسن، و العناية به والخدمات المختلفة التي يحتاجها نظرا لتعدد الاحتياجات والمشكلات التي ترتبط بمرحلة الشيخوخة، ويبدو أن حاجة المسنين في سلطنة عمان لخدمات الرعاية الاجتماعية ضرورة تفرضها عليها تغيرات العصر الحالي من تفيرات أسرية خاصة والمجتمع العماني عامة، فتأتي هذه الدراسة للتعرف على الى أشكال الرعاية المقدمة للمسنين وتقييمها من وجهة الفي نظر المسنين

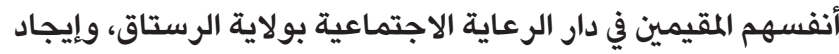
الحلول المناسبة لرفع رضا المسنين وكفاءة الخدمات المقدمة لهم.

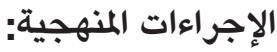

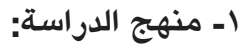

اعتمدت الدراسة على المنهج الوصفي الذي يعتبر أكثر المناهج مناسبة للدراسة، لوصف الظاهرة المدروسة وشفا علميا دقيقا كميا و كيفيا لخدمات الرعاية المقدمة لجميع المسنين المقيمين بالدار، تحقيقا لأهداف الدراسة والإجابة على تساؤلاتها.

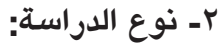
تنتمي الدراسة الحالية إلى نمط الدراسات الوصفية، تلك التي تسعى إلى وصف خصائص ظاهرة معينة، أو موقف محدد أو قضايا اجتماعية تمت دراستها من قبل؛ وذلك من أجل الوصول

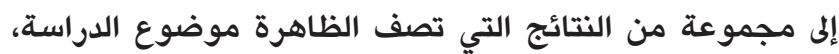

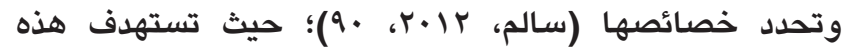
النوعية من الدراسات الحصول على معلومات كافية ودقيقة عن

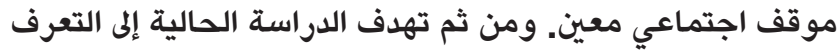

دور الرعاية، و (07) يعيشون وحدهم، وقد وجدت الدراسة

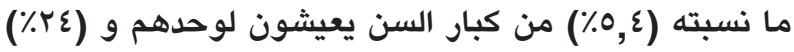

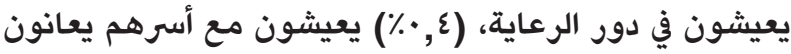
من سوء التغذية، ووجدت الدراسة أن أكثر المسنين الذين يعانون من سوء التغذية هم الذين يعيشون في دور الدور الرعاية. ๑ـ دراسة (Van \& Maes, 2006) و والتي أكدت على أن التدخل

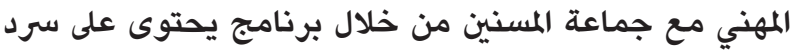

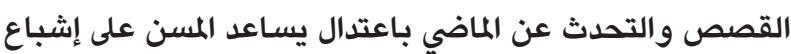
احتياجاته النفسية والاجتماعية، ويؤدى إلى التأثير الإيجابي

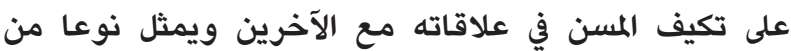
المساندة الاجتماعية للمسنين. 7- دراسة (Rash, 2007)، فقد هدفت إلى تقصي واقع الدعم الاجتماعي ومظاهره وتأثيراته في دور الرعاية في فئ فلوريدا والعوامل الاجتماعية المؤثرة فيه، فأظهرت النتائج أن الدعم الاجتماعي في دور الرعاية في فلوريدا يعتمد على الاختصاصيين

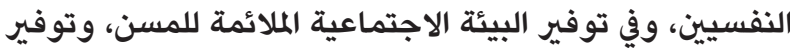

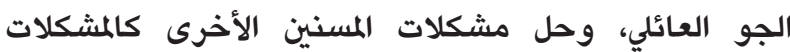
الاقتصادية والصحية. V- دراسة (Sigurdardottir, 2011) أشارت الدراسة لاستخدام الرعاية الرسمية وغير الرسمية لكبار السن التي هدفت إلى التعرف على الظروف المعيشية وطبيعة الرعاية التي يتلقاهـا

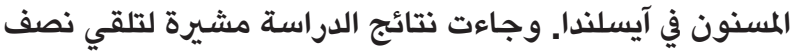
عينة الدراسة من المسنين لرعاية خاصة ويحتاجون لمن يقدم لهم الرعاية والاهتمام. وأن أكثر من النصف منهم يتلقون الدانه

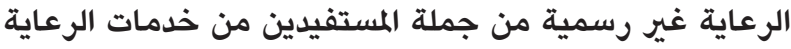

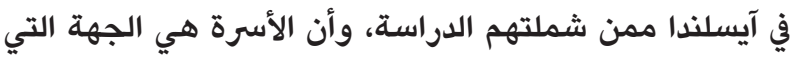
تقدم هذه الرعاية. وكشفت عينة الدراسة عن تأكيد المسنين رغبتهم في أن تقدم لهم الرعاية في منازلهم على الأمد البعيد.

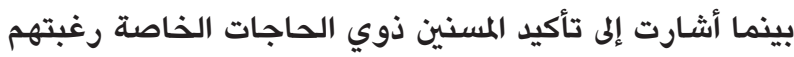
في الرعاية المؤسساتية لصعوبة تقديم الرعاية على المايلى الأسرة

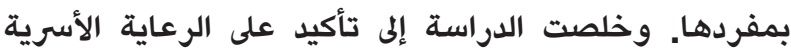

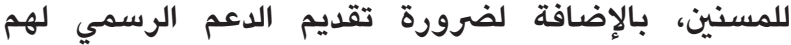

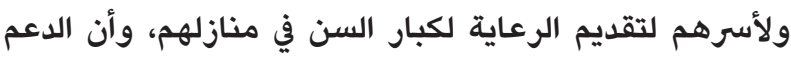

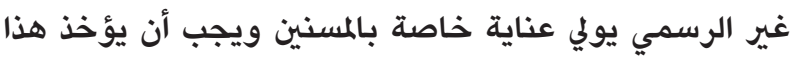
الأمر كنقطة قوة للتخطيط لبرامج رعاية المسنين في آيسلندا. ^- دراسة (Khamngae, et al, 2014) التي تناولت دراسة وكوهة مستوى رضا كبار السن عن سياسة الرعاية الاجتماعية، ودراسة مشاكل سياسة الرعاية الاجتماعية ، ودراسة المبادئ ولئ لاسئ

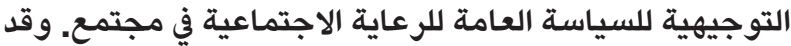

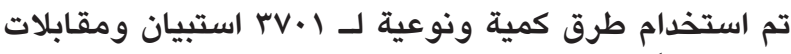

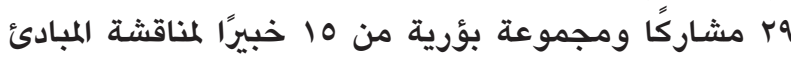
التوجيهية للسياسة. وقد أشارت النتائج الى أن كبار السن كانوا راضين عن سياسة الرعاية الاجتماعية على مستوى معتدل مثل الضمان الاجتماعي والمعرفة والتعليم. ومع ذلك ،

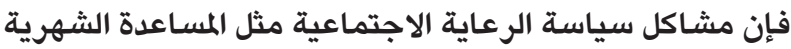




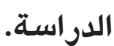

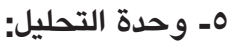
المسنون المقيمون في دار الرعاية الاجتماعية بولاية الرستاق.

7- مجتمع البحث والعينة: تعد دار الرعاية الاجتماعية بالمسنين بولاية الرستاق مجتمعا

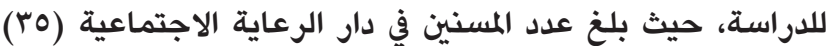
مسنا لكلا النوعين ذكور وإناث، وتم أخذ عينة عشوائية حوالي (Y) مسنًا من كلا النوعين ذكور وإناث؛ إذ لم تتمكن الباحثة من أخذ العينة مسحا شاملا؛ وذلك لأن عددا كبيرًا من المسنين مصابون باختلال عقلي.

نتائج الدراسة ومناقشتها

أولا: الرعاية الصحية

بينت نتائج الجدول (r) تقييم تجربة الرعاية الصحية للمسنين بالدار من وجهة نظر المسنين أنفسهم، مرتبة وفق الترتيب المطروح، حيث تم ترتيب العبارات بناء على المتوسط الحسابي للعبارات، وبلغ المتوسط الحسابي (ب, (1)، في حين بلغ الانحراف

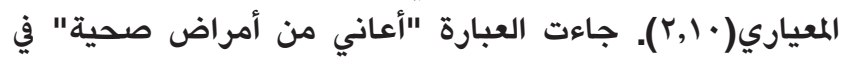

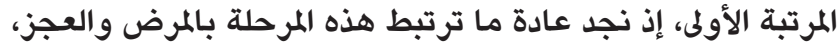
وقد تؤثر صحة المسن الجسمية على العمل والحركة والمشاركة في الأنشطة المختلفة بالدار، وهذا يتفق مع ما وصت بـ به دراسة

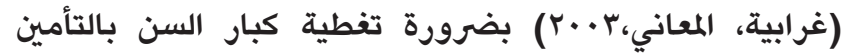
الصحي الشامل، وتوفير الأدوية اللازمة لهم مجانا أو بأسعار منخفضة، وحصلت العبارة "يقدم لي الدار نظاما غذائيا يتناسب الاسويل مع حالتي المرضية" على (أقل تأييد)، إذ لاحظت الباحثة من خلال

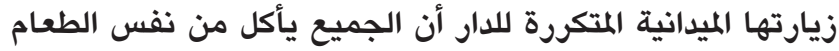

جدول (1) معامل ثبات ألفا كرونباخ لأبعاد الدراسة

\begin{tabular}{|c|c|c|c|}
\hline معامل الثبات & عدد الفقرات & البعد & الرقم \\
\hline$\cdot, \wedge 9$ & 0 & الرعاية الصحية & 1 \\
\hline$\cdot, \wedge r$ & 0 & الرعاية النفسية & $r$ \\
\hline$\cdot, 91$ & 0 & الرعاية الدينية & $r$ \\
\hline$\cdot, 9$. & 0 & الاجتماعية & $\varepsilon$ \\
\hline$\cdot, \wedge \vee$ & 0 & الرعاية الترفيهية & 0 \\
\hline$\cdot, \wedge \wedge$ & $r$. & & بعاد ككل \\
\hline
\end{tabular}

على أشكال الرعاية المقدمة في دار الرعاية الاجتماعية ومدى رضى المسن بالخدمات المقدمة في الدار، وذلك من خلال جمع البيانات المناسبة وتحليلها للوصول إلى مجموعة من النتائج التي تصف الظاهرة المدروسة.

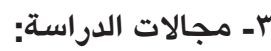
اـ المجال البشري: يعد المقيمون في دار الرعاية الاجتماعية بولاية الرستاق (المسنون) والبالغ عددهم (بالئر) مسنا مجالا بشريا لللدراسة ومن كلا النوعين الذكور والإناث. rـ المجال المكاني: حدد المجال المكاني بدار الرعاية الاجتماعية ولإنية الخاص بالمسنين الواقع في جنوب الباطنة بولاية الرستاق. rـ المجال الزماني: استغرقت عملية جمع البيانات بشكل يومي

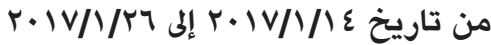

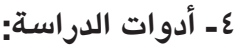
استخدمت ثلاثة أنواع من الأدوات لجمع البيانات وهي: الملاحظة دون المشاركة في وصف الأحداث وسلوكيات المسنين بالدار،

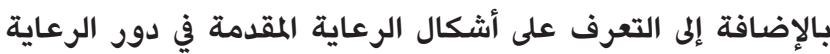

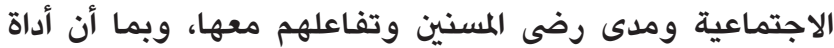

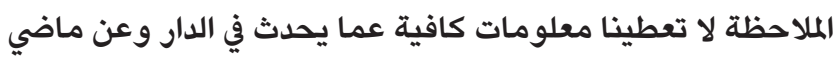
المسنين فيها فقد أجريت استبارا موزعًا على المسنين، ومقابلة مع مدير الدار.

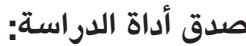
الصدق الظاهري: Fae Validity حيث تم التحقق من صدق الأداة من خلال عرضها في صورتها الأولية على عدد من المحكمين من أعضاء هيئة التدريس بجامعة السلطان قابوس، حيث بلغ عددهم (^) لإبداء ملاحظاتهم حول مدى ملاءمة الفقرات من حيث

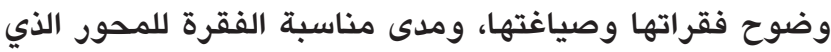
تنتمي إليه، وإضافة وحذف أي عبارات يرونها مناسبة. و وقد قام الباحثون بإجراء التعديلات اللازمة بناء على آراء المحكمين، وتم استبعاد العبارات التي تقل نسبة الاتفاق عليها من الـمحكمين

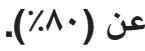

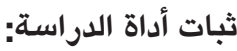
ويظهر من الجدول (1) أن معاملات ثبات الاتساق الداخلي ترواحت بين (ץ, •-- اף, •) وبلغ معامل ألفا كرونباخ للأداة ككل

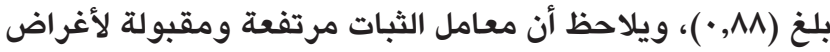

جدول (r) يوضح الرعاية الصحية

\begin{tabular}{|c|c|c|c|c|c|c|c|c|}
\hline \multirow{2}{*}{ ت } & \multirow{2}{*}{ متوسط } & \multicolumn{2}{|c|}{ 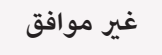 } & \multicolumn{2}{|c|}{ إلى حد ما } & \multicolumn{2}{|c|}{ موافق } & \multirow{2}{*}{ العبــارة } \\
\hline & & $\%$ & ك & $\%$ & ك & $\%$ & ك & \\
\hline 1 & $r, \varepsilon \neg 10$ & $10, \varepsilon$ & r & $r r, 1$ & $r$ & 71,0 & $\wedge$ & يقدم لي الدار نظاما غذائيا يتناسب مع حالتي المرضية. \\
\hline$r$ & r,or^o & $10, \varepsilon$ & r & $10, \varepsilon$ & $r$ & $79, r$ & 9 & يبصرني الدار بما أعانيه من أمراض وما الذي يجب علي اتباعه \\
\hline$r$ & $r, v 79 r$ & $\mathrm{~V}, \mathrm{~V}$ & 1 & $\mathrm{~V}, \mathrm{~V}$ & 1 & $\wedge \varepsilon\rceil$, & 11 & حرص مثرفي الدار لأتناول الأدوية في الوقت المحدد لها. \\
\hline$\varepsilon$ & r,vרar & • & • & $r r, l$ & $r$ & $\vee 7,9$ & $1 \cdot$ & يحرص الدار على متابعة مواعيدي في المستشفى . \\
\hline 0 & r,qrrו & - & • & $\mathrm{v}, \mathrm{V}$ & 1 & $a r, r$ & it & أجد أن حالتي الصحية في هبوط تدريجي \\
\hline \multicolumn{4}{|c|}{ الانحر اف المعياري = ب, r } & \multicolumn{4}{|c|}{ المتوسط الحسابي=|r } & القوة النسبية=•9, • \\
\hline
\end{tabular}




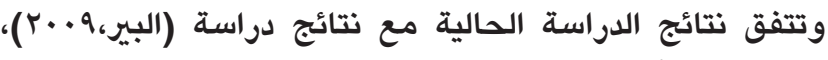

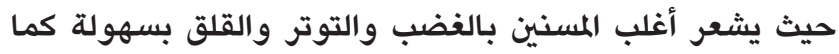

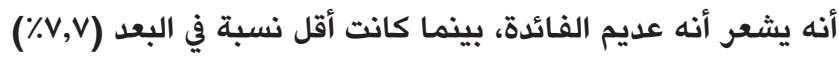

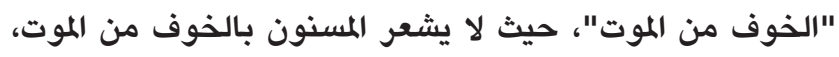

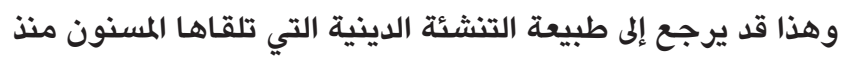

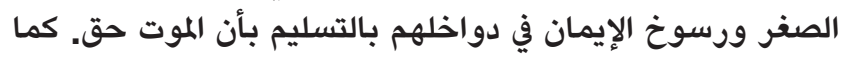

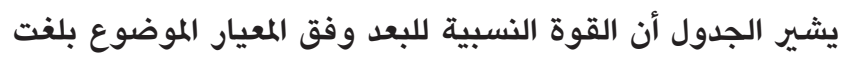

حوالي (Tr\%).

ثالثا: الرعاية الدينية

توضح نتائج الجدول (ع) تقييم تجربة الرعاية الدينية للمسنين

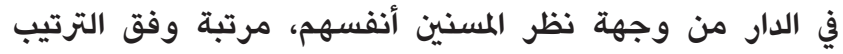

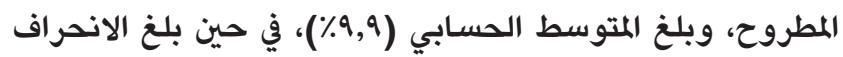

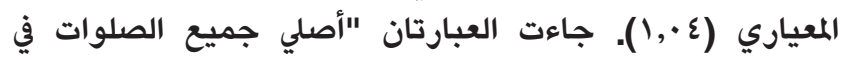

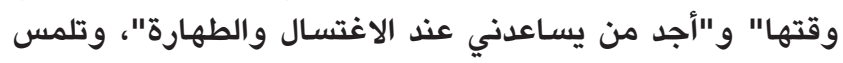
الباحثة محافظة الدار على قدسية الدين الحنيف في ولاني الجانب الأساسي منه كالصلاة وهي عمود الدافي الدين،

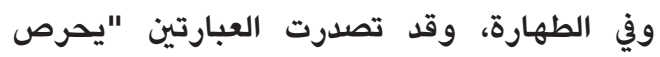

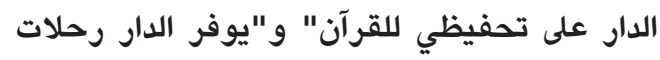

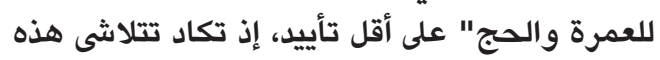

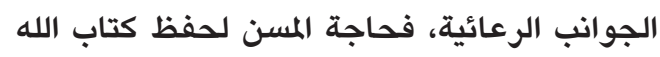

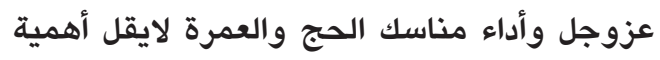

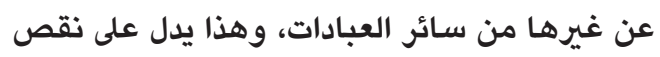

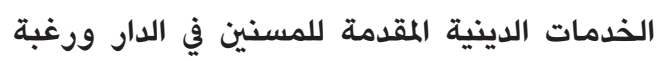
المسنين في توفرها، كما وجد أن القوة النسبية للبعد المقدي وفق المعيار الموضوع هي قزية بلغت حوالي (77٪).

رابعا: الرعاية الاجتماعية

بينت نتائج الجدول (0) تقييم تجربة الإيماعية الرعاية

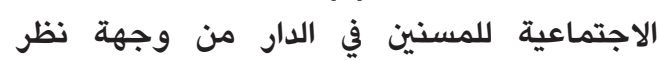

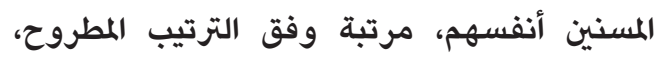

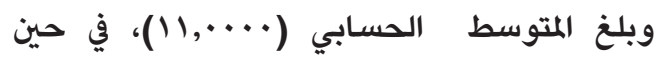

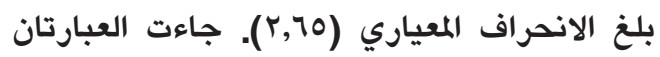

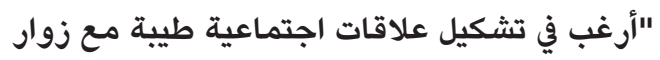

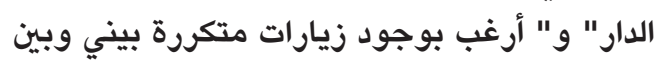
أصدقائي"، إذ أن المسن بحاجة إلى العيش ضون ضئ

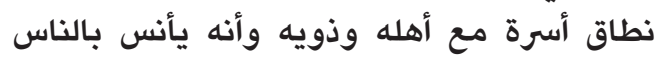

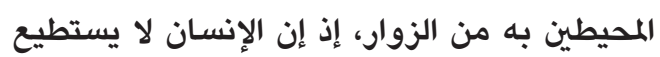

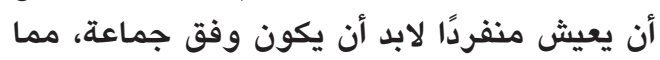

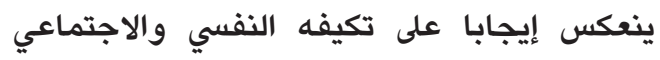
معا، كما صرح المسنين أثناء مقابلتهم أن المسن ولنه

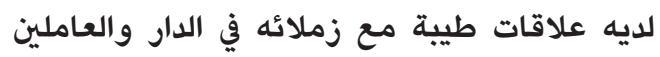

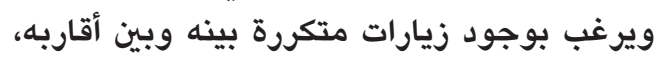

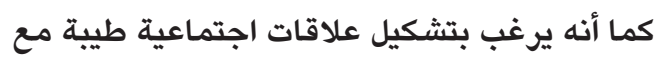

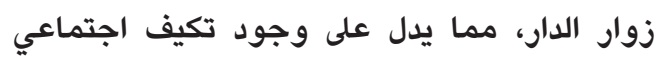
لدى المسنين المقيمين بالدار، وأن المسن مرتبط ليط الدئ

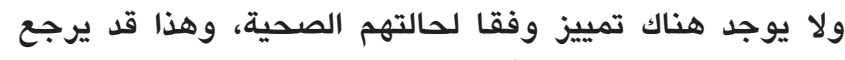

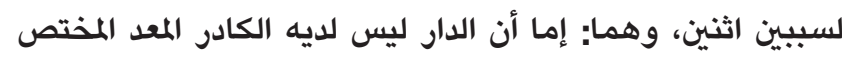

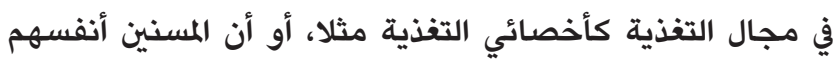

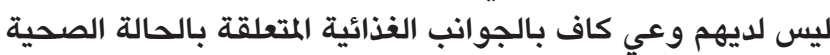

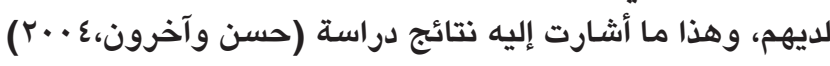

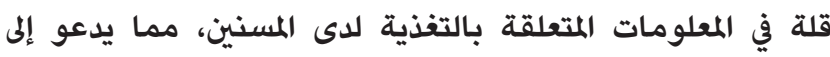

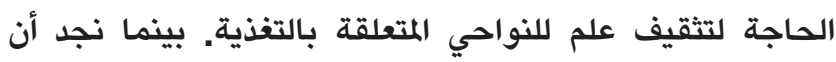

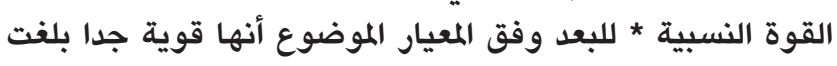

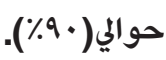
ثانيا: الرعاية النفسية بينت نتائج الجدول (r) تقييم تجربة الرعاية الفراية النفسية للمسنين

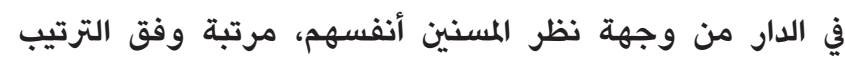

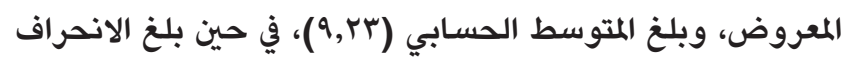

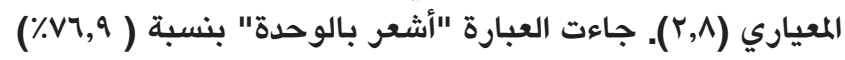
جدول (r) يوضح الرعاية النفسية

\begin{tabular}{|c|c|c|c|c|c|c|c|c|}
\hline \multirow[b]{2}{*}{ ت } & \multirow{2}{*}{ متوسط } & \multicolumn{2}{|c|}{ غير موافق } & \multicolumn{2}{|c|}{ إلى حد ما } & \multicolumn{2}{|c|}{ موافق } & \multirow{2}{*}{ العبـــــــــــــة } \\
\hline & & $\%$ & ك & $\%$ & ك & $\%$ & ك & \\
\hline 0 & $1, \cdot v 79$ & $9 r, r$ & it & $\mathrm{v}, \mathrm{V}$ & 1 & $\mathbf{0}$ & • & الخوف من الموت. \\
\hline$\varepsilon$ & 1,7arr & $\varepsilon \eta, r$ & 1 & $r \wedge, 0$ & 0 & $10, \varepsilon$ & r & أشعر بأن ليس لي فائدة في الحياة \\
\hline$r$ & 1,V7ar & or,, 1 & $v$ & $10, \varepsilon$ & $r$ & $r \cdot, \wedge$ & $\varepsilon$ & أنظر إلى الحياة بنظرة سوداوية \\
\hline$r$ & r,lorA & $r \cdot, \wedge$ & $\varepsilon$ & $r r, l$ & r & $\varepsilon 7, r$ & 7 & اشعر بالتوتر وعدم القدرة على \\
\hline 1 & r,OY^o & $r r, 1$ & r & - & . & $v 7,9$ & 1. & اشعر بالوحدة \\
\hline \multicolumn{4}{|c|}{ الانحراف المعياري = r,A } & \multicolumn{4}{|c|}{ المتوسط الحسابي = r } & القوة النسبية = r TT, \\
\hline
\end{tabular}
جدول (ع) يوضح الرعاية الدينية

\begin{tabular}{|c|c|c|c|c|c|c|c|c|}
\hline \multirow{2}{*}{$\Xi$} & \multirow{2}{*}{ متوسط } & \multicolumn{2}{|c|}{ غير موافق } & \multicolumn{2}{|c|}{ إلى حد ما } & \multicolumn{2}{|c|}{ 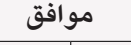 } & \multirow{2}{*}{ العبــــــــــارة } \\
\hline & & $\%$ & ك & $\%$ & ك & $\%$ & ك & \\
\hline 1 & $1, \cdots$ & $1 \cdots, \cdot$ & ir & $\cdot$ & - & • & $\cdot$ & يوفر الدار رحلات للعمرة والحج \\
\hline$r$ & $1, \cdots$ & $1 \cdots, \cdot$ & ir & • & • & • & • & يحرص الدار على تحفيظي للقرآن. \\
\hline$r$ & $r, \cdot v 7 q$ & $r \wedge, 0$ & $\circ$ & $10, \varepsilon$ & r & $\varepsilon 7, r$ & 7 & يقيم الدار محاضرات دينية بين \\
\hline$\varepsilon$ & r,9rm & $\cdot$ & $\cdot$ & $\mathrm{V}, \mathrm{V}$ & 1 & $9 r, r$ & ir & أجد من يساعدني عند الاغتسال و \\
\hline$\circ$ & r,9RMI & - & $\cdot$ & $\mathrm{V}, \mathrm{V}$ & 1 & $9 r, r$ & ir & أصلي جميع الصلوات في وقتها \\
\hline \multicolumn{4}{|c|}{ الانحراف المعياري = ع •, ا } & \multicolumn{4}{|c|}{ المتوسط الحسابي=9,१ } & القوة النسبية=17, · \\
\hline
\end{tabular}

\begin{tabular}{|c|c|c|c|c|c|c|c|c|}
\hline \multicolumn{9}{|c|}{ جدول (0) يوضح الرعاية الاجتماعية } \\
\hline \multirow{2}{*}{ ت } & \multirow{2}{*}{ 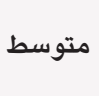 } & \multicolumn{2}{|c|}{ غير موافق } & \multicolumn{2}{|c|}{ 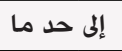 } & \multicolumn{2}{|c|}{ موافق } & \multirow{2}{*}{ العبــــــــــارة } \\
\hline & & $\%$ & ك & $\%$ & ك & $\%$ & ك & \\
\hline$\circ$ & $1, r \wedge \varepsilon 7$ & $v 7,9$ & 1. & $\mathrm{v}, \mathrm{V}$ & 1 & $10, \varepsilon$ & $r$ & أرغب في العيش مع أسرة بديلة . \\
\hline$\varepsilon$ & r,lorA & $r \cdot, \wedge$ & $\varepsilon$ & $r$ r,l & r & $\varepsilon\urcorner, r$ & 7 & أشعر بالانتماء الاجتماعي داخل \\
\hline r & $r, r \wedge \varepsilon \neg$ & $10, \varepsilon$ & r & $r \cdot, \wedge$ & $\varepsilon$ & or, , & $v$ & لدملائي علاقات الدار والعاملية طينة فيها مع \\
\hline r & r,orno & $10, \varepsilon$ & r & $10, \varepsilon$ & r & $79, r$ & 9 & أرغب بوجود زيارات متكررة بيني \\
\hline 1 & r,or^o & $10, \varepsilon$ & r & $10, \varepsilon$ & r & $79, r$ & 9 & أرغب في تشكيل علاقات اجتماعية \\
\hline \multicolumn{4}{|c|}{ الانحر اف المعياري = r,70 } & \multicolumn{4}{|c|}{ 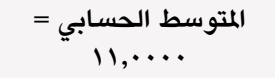 } & القوة النسبية=Vr, • \\
\hline
\end{tabular}


مشتركة مع الجامعات والكليات والمعاهد وغيرها من المؤسسات

وجمعيات المرأة العمانية.

كما يضيف المياحي بأن هناك شروطا للالتحاق بالدار وهي: - ل الا يوجد لديه قريب ملزم بالدرجة الأولى.

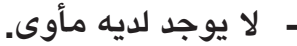

- لا يوجد أحد يرعاه ولا أحد يوفر لـ له الرعاية الأساسية. - إذا كان يعيش في أسرة تعاني من التفكك الأسري. - - الموافقة من معالي الوزير أو الوكيل. كما صرح بأن أي مسن يتقاضى راتبا شهريا من قبل التنمية التوزية الاجتماعية فإنه يقطع عند دخوله للدار؛ وذلك لأن الدار يقدم كل أنواع الرعاية للمسن، وفي حالة وجود أسرة بديلة يتم إرجاع الراتب.

النتائج العامة للدراسة: - يواجه المسنون قصورا في خدمات الرعاية الصحية، والنفسية، والاجتماعية، والترفيهية، والدينية. - أظهرت نتائج تقييم تجربة الرعاية الصحية من قبل المسنين والديه وليه جدول (V) يوضح القوة النسبية لكافة الأبعاد

\begin{tabular}{|c|c|c|}
\hline درجة البعد & القوة النسبية & البعد البع \\
\hline قوي جدا & $\cdot, 9$. & الرعاية الصحية \\
\hline متوسط & • & الرعاية النفسية \\
\hline قوي & $\cdot, 77$ & الرعاية الدينية \\
\hline قوي & $\cdot, \mathrm{Vr}$ & الرعاية الاجتماعية \\
\hline ق ق قوي & $\cdot, \mathrm{v} \wedge$ & الرعاية الترفيهية \\
\hline
\end{tabular}

الشكل (1) يوضح القوة النسبية لكافة الأبعاد

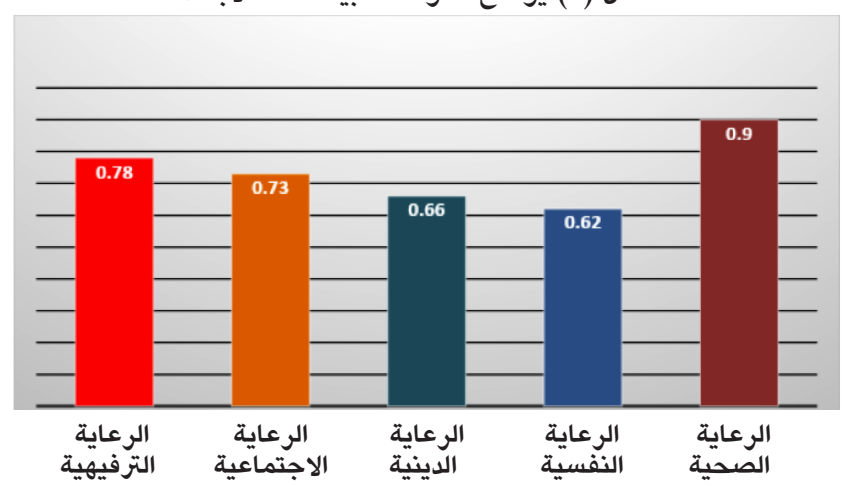

جدول (1) يوضح الرعاية الترفيهية

\begin{tabular}{|c|c|c|c|c|c|c|c|c|}
\hline \multirow{2}{*}{ ت } & \multirow{2}{*}{ متوسط } & \multicolumn{2}{|c|}{ غير موافق } & \multicolumn{2}{|c|}{ 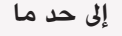 } & \multicolumn{2}{|c|}{ موافق } & \multirow{2}{*}{ العبـــــــــارة } \\
\hline & & $\%$ & ك & $\%$ & ك & $\%$ & ك & \\
\hline 0 & $1,\{710$ & v1, 9 & 1 . & $\mathbf{0}$ & - & $r+1$ & $r$ & يتيح لي الدار فرصة الذهاب إلى \\
\hline$\varepsilon$ & r,IOHA & $r \cdot, \wedge$ & $\varepsilon$ & $r, 1$ & $r$ & $\varepsilon \eta, r$ & 1 & يقدم الدار رحلات ترفيهية بشكل \\
\hline$r$ & $r, r \wedge \varepsilon T$ & $r r, 1$ & r & $10, \varepsilon$ & $r$ & 71,0 & $\wedge$ & يوفر لي الدار الراديو والتلفـاز \\
\hline r & $r, \wedge \varepsilon 7 r$ & $\mathbf{0}$ & 0 & $10, \varepsilon$ & r & $\wedge \varepsilon, \uparrow$ & 11 & أقضي يومي في التجول في ساحة او \\
\hline 1 & r,QYMI & - & • & $v, v$ & 1 & $9 r, r$ & ir & أفرح عندما يسمح الدار بزيارة \\
\hline \multicolumn{4}{|c|}{ الانحراف المعياري = 1,79 } & \multicolumn{4}{|c|}{ المتوسط الحسابي=VVV } & القوة النسبية=V^,· \\
\hline
\end{tabular}

بالرحم الاجتماعي؛ ذلك ينعكس إيجابا عليه، وهذا ما أثبتته

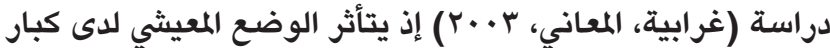

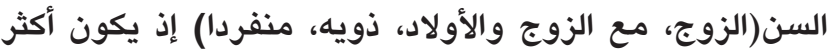
إيجابية لدى المسنين الذين يعيشون مع أزواجهم أو أزواجهم

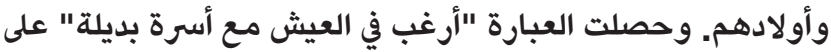
أقل متوسط حسابي من بين العبارات المطروحة، وترى الباحثة أنه قد يدل على حسن الخدمات المقدمة في الدار، وتشير إلى كرامة

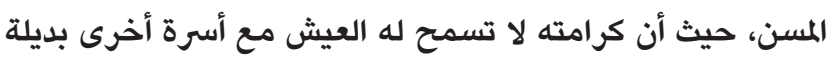

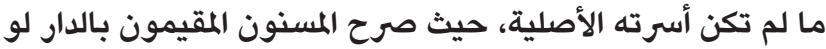

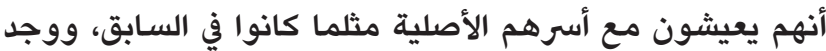

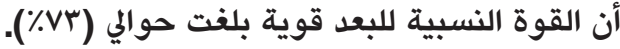

خامسا: الرعاية الترفيهية بينت نتائج الجدول (7) تقييم تجربة الرعاية الترفيهية للمسنين في الدار من وجهة نظر المسنين أنفسهم، مرتبة وفق الترتيب

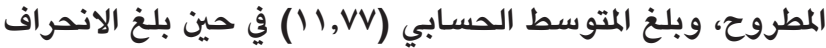
المعياري (79 (1)، جاءت العبارة "أفرح عندما يسمح الدار بزيارة

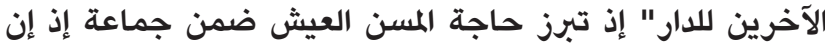

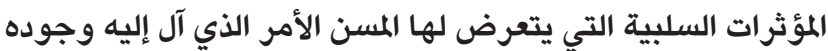
في الدار، فغياب الزوج والأولاد والجيران وغيرهم يجعل المسن بحاجة لتعويض مثل الفقد وإشباع الحاجة لديه فيقوم بتحويل تلك المشاعر إيجابا على الزوار على اعتبار أنهم يعوضونه هذا الفقد ويأنس بهم، فتزداد حاجة الإنسان للتقدير عند تقدمه في العمر ويكون مسنا، وجاءت في الترتيب الأخير عبارة "يتيح لي الدار فرصة الذهاب إلى السوق" ترى الباحثة أهمية دمج المسن مع العالم الخارجي، فهو يتسوق كي يلبي احتياجاته الناقصة ويرفهه عن نفسه ويتفاعل مع المحيطين من حوله، ثم أن الباحثة ئهي رصدت ملاحظتها حول هذا النوع من الرعاية فوجدت قصورا واضحا فيها وفي شغل أوقات الفراغ لدى المسنين بالدار. كما قامت الباحثة بإجراء اختبار T-test للتعرف فيما إذا كانت هناك فروق إحصائية ذات دلالة معنوية بين النوع والعبارات

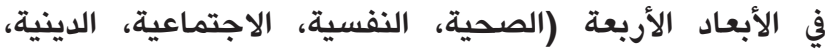
الترفيهية)، وأوضحت النتائج عدم وجود فروق إحصائية ذات دلالة معنوية.

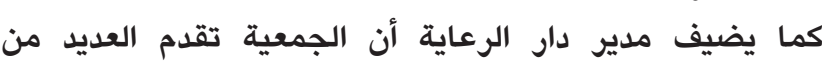

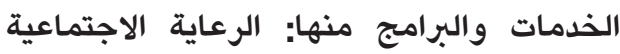

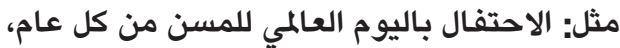
والاحتفال بالعيد الوطني من كل عام، واستقبال الزوار من داخل وخارج السلطنة، كذلك الرعاية الثقافية مثل: تنفيذ ندوات ومحاضرات دورات ودروس

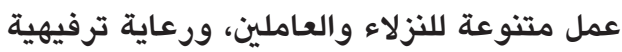
متمثلة في تنفيذ رحلات ترفيها للنزلاء في المواقع السياحية، وأيضا رعاية غذائية مثل: تنفيذ وجبة رحلات ترفية إفطار جماعية في شهر رمضان، وأخيرا يقدم الدار رعاية مجتمعية متمثلة في تنفيذ فعاليات 
17) تكثيف وسائل الإعلام للتوعية بفئة المسنين وأهميتها في

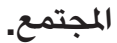

V الاستفادة من خبرات المسنين وتجاربهم في الحياة والقصص

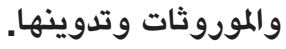

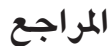

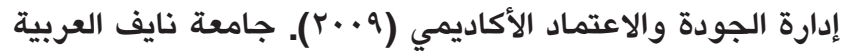

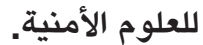

العسكري، سليم (10 (ץ). الضغوط الحياتية والقلق والاكتئاب لدى عينة من المسنين بسلطنة عمان، رسالة ماجستير غير الماني منشورة، كلية الآداب، قسم علم النفس، جامعة المنصورة، مصر.

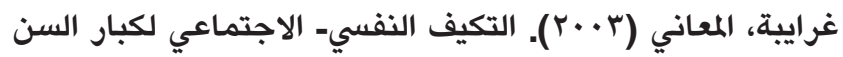
المشتركين في الضمان الاجتماعي في محافظة العاصمة/ عمان.

القصابي، هلال (r إr). المشكلات النفسية والاجتماعية لدى

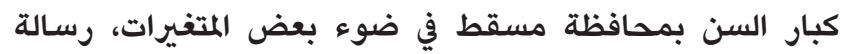
ماجستير غير منشورة، كلية الآداب والدراسات الإسلامية، جامعة فئة

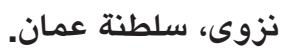

الخاطرية، رقية (r (ب). مخاوف المسنين في المجتمع العماني

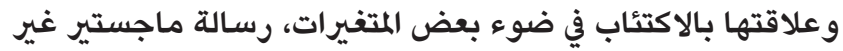
منشورة، كلية الآداب والعلوم الإنسانية، قسم التربية والدراسات الإنسانية، جامعة نزوى، سلطنة عمان.

الصواعية، أسماء (10 (r). مؤشرات تخطيطية لتطوير خدمات الرعاية الاجتماعية للمسنين في المجتمع العماني دراسة مطبقة

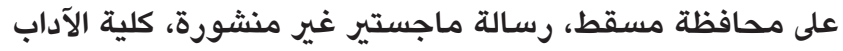
والعلوم الاجتماعية، قسم العلم والعمل الاجتماعي، جامعة فيرة السلطان قابوس، سلطنة عمان.

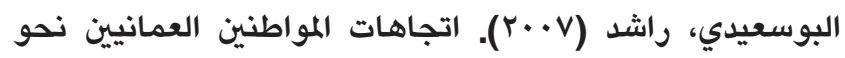

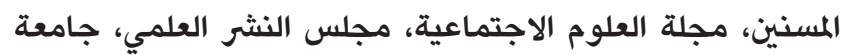

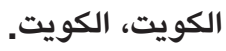

حسن، أسماء (11)

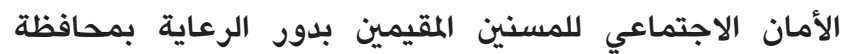
القاهرة، مجلة دراسات الخدمة الاجتماعية والعلوم الإنسانية، لإعاية

مصر.

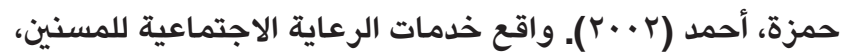

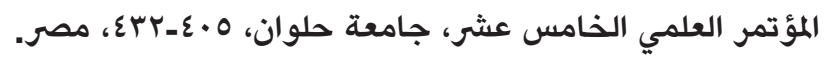

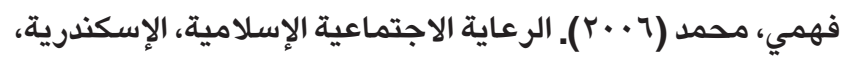

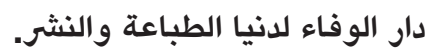

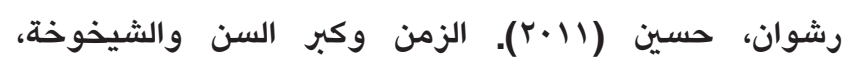

أنفسهم أنها ذات قوة نسبية قوية جدا، حيث بلغت القوة النسبية للبعد (•9٪)، هذا بالإضافة إلى المتوسط الحسابي

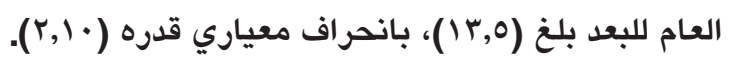

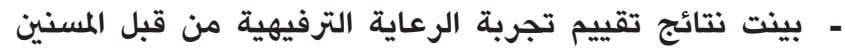
أنفسهم أنها ذات قوة نسبية قوية، حيث بلغت النتاعية القوة النسبية

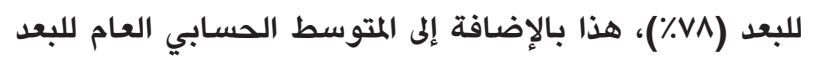

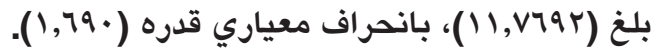

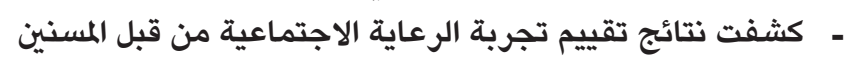

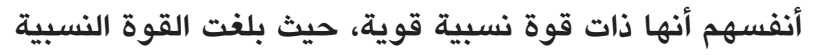

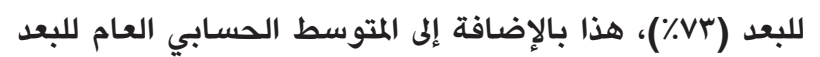

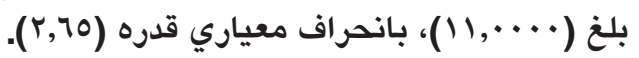
- أظهرت نتائج تقييم تجربة الرعاية الدينية من قبل المسنين

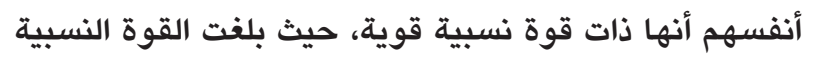

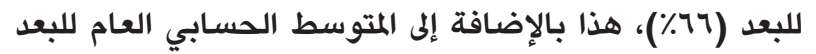

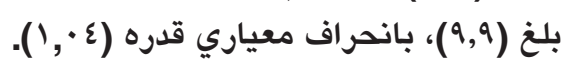

- كشفت نتائج تقييم تجربة الرعاية النفسية من قبل المسنين

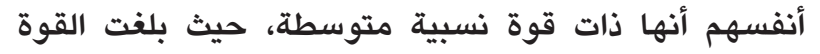
النسبية للبعد (r/\%)، هذا بالإضافة إلى المتوسط الحسابي

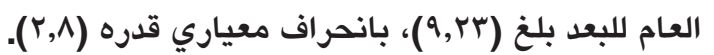

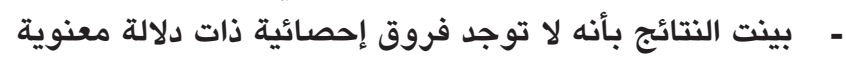
بين النوع والعبارات في الأبعاد الأربعة (الصحية، النفسية،

الاجتماعية، الدينية، الترفيهية).

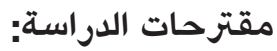
() توفير أخصائية تغذية في الدار حتى تثرفي الدف على الوجبات التي تتناسب مع الحالة الصحية لكل مسن ومتابعة طرق التفذية وجودتها ونوعية العناصر الغذائية المقدمة للمسن.

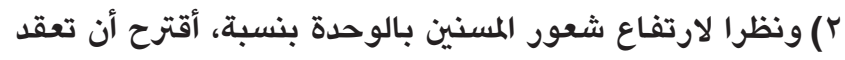

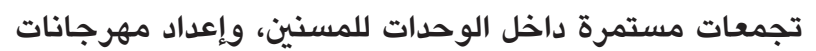

متنوعة ودعوة الآخرين للمشاركة فيها.

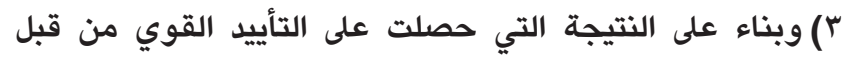

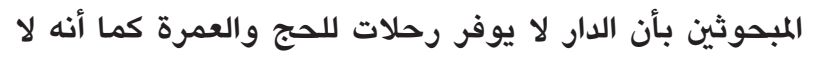
يحرص على تحفيظهم القرآن الكريم، أقترح تعيين مرشد ديني

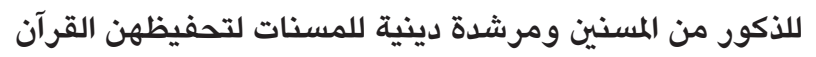

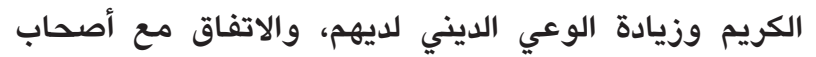

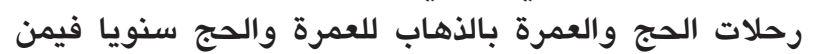
يكون قادرا على الذهاب ويتم ذلك بالترة بالتيب.

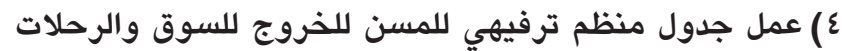
والتجمعات خارج الدار تحت إثراف الدار وقيادتهم، وهذا مما يرفع من جعل المسن يشعر بالصحة النفسية ويقلل من الشعور بالوحدة. أاقترح لمن لديه أسرة من المسنين المقيمين في الدار إجبارهم على الورة زيارته على الأقل في الشهر مرة. () توفير أماكن لاجتماع المسنين مع بعضهم البعض مض مع مسنين

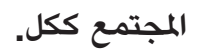


الفلسطينيين في بيوت المسنين ونوادي المسنين وفي البيوت في محافظة بيت لحم، المجلة الأردنية للعلوم الاجتماعية، الجامعة الماني

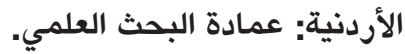

إبراهيم، قصي (9 (r). مشكلات المسنين في المجتمع الفلسطيني

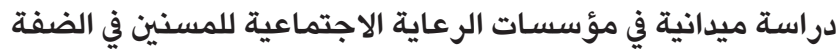
الغربية، رسالة ماجستير منشورة، معهد البحوث والداعة الدراسات العربية، القاهرة، مصر. مجلة جامعة أم القرى، المجلد الثاني،

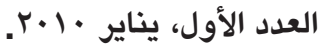

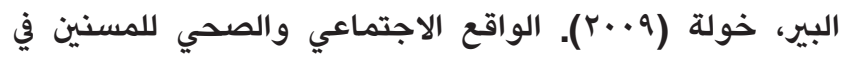
العراق وسبل تطويره، وزارة التخطيط والتعاون الإنمائي، دائرة التنمية البشرية، جمهورية العراق.

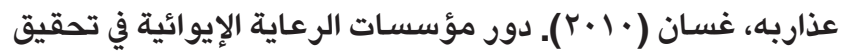
التكيف الاجتماعي للمسنين في الأردن: دراسة ميدانية مسحية الإنية للمسنين في الدور الإيوائية في مدينة عمان، رسالة الإدين داجستير غير الإني منشورة، جامعة اليرموك، كلية الآداب، إربد، الأردن.

الجرجاوي، زياد (r +.r). أبعاد الرعاية التربوية للمسنين: رؤية إسلامية، مجلة جامعة الأقصى- سلسلة العلوم الإنسانية- جامعة الرعاية

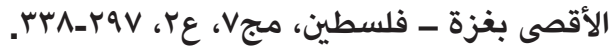

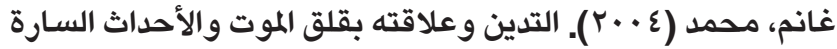
والنظرة للحياة دراسة نفسية مقارنة بين المسنين والمسنات،

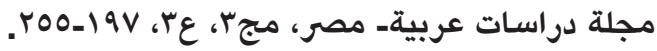

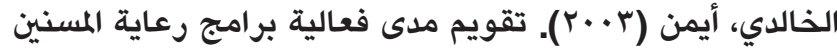
في الأردن دراسة حالة: دار الضيافة لرعاية المسنين، رسالة ماجستير غير منشورة، كلية الدراسات العليا، الأردن.

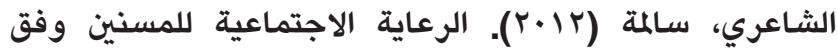
الشريعة الإسلامية، ليبيا، الحكمة للطباعة والنشر.

Anat Freund, Tova Band-Winterstein (2017). Social Workers' Attempts to Navigate Among the Elderly, Their Families, and Foreign Home Care Workers in the Haredi Community, Journal of Applied Gerontolgy, 38 (4).

Creanza, A., Mcwhirter, J. (2003). Group Work and its Effectiveness on Improving Adaptation among Senior Citizens in Virginia State, Journal for Specialists in Group Work, 28 (3), 201-210.

Himes, Christine (2001). Rapidly Aging: US society face complex issue, Population Bulletin, 56 (4).
الإسكندرية، مركز الإسكندرية للكتاب.

سالم سماح، صبحي سمر، جابر أمل (10 (Y). ممارسة الخدمة الاجتماعية مع المسنين، دار المسرة.

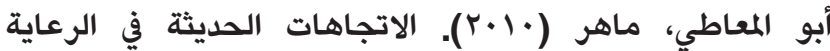
الاجتماعية أسس نظرية ونماذج عربية ومصرية، حلوان مصر،

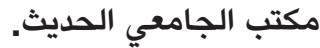

فهمي، محمد (r (r). الرعاية الاجتماعية وخصخصة الخدمات، الإسكندرية، المكتب الجامعي الحديث.

شحاته، محمود (ع (ب). مؤتمر حقوق المسنين بين الواقع والمأمول، مركز جامعة القاهرة، جامعة القاهرة.

أبو المعاطي، ماهر، عا.ب، الخدمة الاجتماعية في مجال رعاية المسنين، الرياض، دار الزهر اءع.

منصور، عزمي (•(ب). كبار السن بين الواقع والطموح، كنوز المعرفة، جامعة عمان الأهلية.

محمود أكرم، إبراهيم مروان (ع إr). الرعاية الشاملة للمسنين "رياضيا، اجتماعيا، صحيا، نفسيا، تأهيل"، المملكة الأردنية

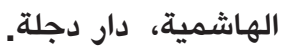

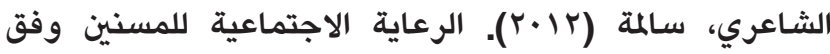
الشريعة الإسلامية، ليبيا، دار الحكمة.

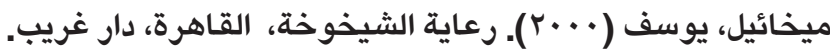
فهمي، محمد (T/ (T). الرعاية الاجتماعية والنفسية للمسنين، الإسكندرية، المكتب الجامعي الحديث. الرعاية الاحتماع.

عبد اللطيف، رشاد (1+(Y). في بيتنا مسن مدخل اجتماعي متكامل، دار الوفاء لدنيا الطباعة والنثر، الإسكندرية.

وزارة التنمية الاجتماعية (17) بارب). دار الرعاية الاجتماعية

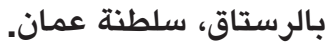

السعوي، محمد (17 (ب). رعاية المسنين بين القطاعين الحكومي والأهلي: دراسة مقارنة مطبقة في منطقة القصيم، المجلة العربية

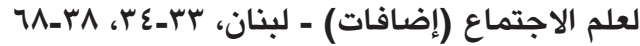

الكندري؛ يعقوب؛ كروز (17 (†). الاختلافات الصحية بحسب الجنس والخصائص الاجتماعية بين المسنين الكويتيين، مجلة الإنية

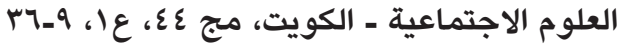
كتلو، كامل؛ العرجا، ناهد (7) (17). الصحة النفسية لدى المسنين الفلسطينيين: دراسة ميدانية لواقع الصحة النفسية لدى المسنين 
Khamngae, et al (2014). Social Welfare Needs and Policies for Elderly People in Thailand: A Case Study in Pitsanulok Community, Asian Social Science, 10 (12).

Rash, E. M. (2007). Social Support in Elderly Nursing Home Populations: Manifestations and Influences. Qualitative Report, 12 (3), 375-396.

Van puyenbrock \& Maes Bea (2006). Pronoun Development of, Group work for aging people with intellectual, Journal of intellectual and developmental disability, Vol. 31. 